\title{
The mGluR2 Positive Allosteric Modulator BINA Decreases Cocaine Self-Administration and Cue-Induced Cocaine-Seeking and Counteracts Cocaine-Induced Enhancement of Brain Reward Function in Rats
}

\author{
Xinchun Jin ${ }^{1,4}$, Svetlana Semenova',4, Li Yang ${ }^{2}$, Robert Ardecky ${ }^{2}$, Douglas J Sheffler ${ }^{3}$, Russell Dahl ${ }^{2}$, \\ P Jeffrey Conn ${ }^{3}$, Nicholas DP Cosford ${ }^{2}$ and Athina Markou*, \\ 'Department of Psychiatry, School of Medicine, University of California San Diego, La Jolla, CA, USA; ${ }^{2}$ Program on Apoptosis and Cell Death, \\ Sanford-Burnham Medical Research Institute, La Jolla, CA, USA; ${ }^{3}$ Department of Pharmacology, Vanderbilt University Medical Center, Nashville, \\ TN, USA
}

\begin{abstract}
Metabotropic glutamate receptor 2/3 (mGluR2/3) agonists were shown previously to nonselectively decrease both cocaine- and food-maintained responding in rats. mGluR2 positive allosteric modulators (PAMs) may represent improved therapeutic compounds because of their modulatory properties and higher selectivity for mGluR2. We analyzed the effects of the selective, brain penetrant, and systemically active mGluR2 PAM potassium 3'-([(2-cyclopentyl-6-7-dimethyl- I-oxo-2,3-dihydro- | H-inden-5-yl)oxy]methyl)biphenyl I-4-carboxylate (BINA) and the mGluR2/3 agonist LY379268 on intravenous cocaine self-administration and cocaine-seeking behavior in rats that had short $(\mathrm{I}$, ShA) or long $(6 \mathrm{~h}, \mathrm{LgA})$ access to cocaine. The effects of BINA on food responding and food-seeking behavior were also analyzed. Finally, we examined the effects of BINA on brain reward function and cocaine-induced reward enhancement using the intracranial self-stimulation procedure. BINA decreased cocaine self-administration in both ShA and LgA rats, with no effect on food self-administration. Alternatively, LY379268 nonselectively decreased both cocaine and food self-administration. BINA decreased cue-induced reinstatement of cocaine seeking with no effect on food seeking. The cocaine-induced enhancement of brain reward function was blocked by BINA, although the highest doses of BINA decreased brain reward function when administered alone, suggesting additive, rather than interactive, effects of BINA and cocaine. In conclusion, BINA attenuated the reinforcing and counteracted the reward-enhancing effects of cocaine and decreased cue-induced cocaine-seeking behavior, without affecting behaviors motivated by food reinforcement. The higher selectivity of BINA compared with an mGluR2/3 agonist for drug- vs food-motivated behaviors suggests a therapeutic role for mGluR2 PAMs for the treatment of cocaine addiction and possibly other drugs of abuse.

Neuropsychopharmacology (2010) 35, 202 I-2036; doi:I0.1038/npp.2010.82; published online 16 June 2010
\end{abstract}

Keywords: glutamate; LY379268; intracranial self-stimulation; food seeking; food responding; BINA

\section{INTRODUCTION}

Cocaine addiction, a chronic relapsing disorder, remains a major public health problem in the United States (O'Brien and McLellan, 1996; Leshner, 1997; Ohishi et al, 1998; Dackis and O'Brien, 2001), showing the unmet need for novel treatments for cocaine addiction (O'Brien and Gardner, 2005). Several sources of motivation contribute to the maintenance of cocaine abuse. Specifically, the

*Correspondence: Dr A Markou, Department of Psychiatry, M/C 0603, School of Medicine, University of California San Diego, 9500 Gilman Drive, La Jolla, CA 92093-0603, USA, Tel: + I 858534 I572,

Fax: + | 858534 99|7, E-mail: amarkou@ucsd.edu

${ }^{4}$ These authors contributed equally to this work.

Received 26 January 20 I0; revised II May 20I0; accepted II May 2010 rewarding properties of abused drugs lead to a progressive escalation in the frequency and intensity of drug use, one of the major behavioral phenomena characterizing the development of addiction (American Psychiatric Association, 1994; for review, see Koob et al, 2004; Koob, 2009). In animal experiments, rats that have extended/long access to intravenous cocaine self-administration increase their intake over days, closely mimicking the human condition of increased compulsive drug use (Ahmed and Koob, 1998; Ahmed et al, 2002).

In addition, cocaine amplifies reward signals in the brain, an effect common with other drugs of abuse (Robbins et al, 1983; Taylor and Robbins, 1986; Phillips and Fibiger, 1990; Rice and Cragg, 2004). Furthermore, the reward-enhancing actions of cocaine may partially account for its intrinsic rewarding properties and reflect how psychostimulant 
drugs, including cocaine, increase sensitivity to non-drug rewarding environmental stimuli (Harrison et al, 2002; Chaudhri et al, 2006; Kenny and Markou, 2006; Kenny, 2007). Specifically, in the intracranial self-stimulation (ICSS) procedure, cocaine administration lowers reward thresholds in rats (Esposito et al, 1978; Frank et al, 1988; Kokkinidis and McCarter, 1990; Markou and Koob, 1992; Kenny et al, 2003, 2006), reflecting cocaine-induced enhancement of the rewarding effects of the stimulation.

Finally, chronic vulnerability to relapse contributes to the maintenance of cocaine abuse (Weiss, 2005; Epstein et al, 2006). The presentation of environmental stimuli previously associated with drug taking can precipitate drug craving and relapse to drug use in humans (O'Brien and McLellan, 1996; O'Brien et al, 1998; Dackis and O'Brien, 2001) and may elicit cocaine-seeking behaviors, leading to the reinstatement of cocaine self-administration in animals (eg, Markou et al, 1993; Katz and Higgins, 2003; Epstein et al, 2006). Recent findings suggest that the neuronal mechanisms underlying drug self-administration are different from those mediating relapse vulnerability during abstinence (Shalev et al, 2002; Kalivas and Volkow, 2005; Shiffman et al, 2006). Therefore, in the assessment of the putative therapeutic effects of new compounds, examining the effects of the compounds on the different aspects of cocaine dependence is important.

Recent findings suggest that neuroadaptations in glutamatergic transmission induced by repeated exposure to cocaine or other drugs of abuse are likely to contribute to the maintenance of addictive behaviors, including drug use, craving, and relapse to drug taking in humans (Kalivas and Duffy, 1998; Mansvelder and McGehee, 2000; Ungless et al, 2001; Kalivas, 2004, 2009; Kenny and Markou, 2004; Markou, 2007; Gass and Olive, 2008; Knackstedt and Kalivas, 2009). Specifically, repeated cocaine exposure alters the function of group II metabotropic glutamate receptors (mGluRs). Group II mGluRs, comprising mGluR2 and mGluR3, are predominantly found presynaptically (Schoepp, 2001) and modulate presynaptic glutamate release (Conn and Pin, 1997; Anwyl, 1999; Cartmell and Schoepp, 2000). High levels of group II receptor binding are found in brain regions implicated in different aspects of drug abuse and dependence, suggesting a possible role for mGluR2/3 subtypes in the development of cocaine dependence (Baptista et al, 2004; Kenny and Markou, 2004; Lee et al, 2005; Weiss, 2005; Adewale et al, 2006; Peters and Kalivas, 2006; Aujla et al, 2008; Gass and Olive, 2008; Knackstedt and Kalivas, 2009). Supporting the hypothesis that the rewarding effects of cocaine are partially mediated by cocaine-induced increases in glutamate transmission, the mGluR2/3 agonist LY379268 decreased glutamate levels (Xi et al, 2002a) and attenuated cocaine self-administration in rats (Baptista et al, 2004) and squirrel monkeys (Adewale et al, 2006). Although LY379268 attenuated cocaine-seeking behavior (Baptista et al, 2004; Peters and Kalivas, 2006), it also inhibited responding for food and food-seeking behavior (Baptista et al, 2004; Bossert et al, 2006b; Peters and Kalivas, 2006; Liechti et al, 2007), indicating nonselective actions of mGluR2/3 agonists on responding for drug and non-drug reinforcers. Altogether, the above findings strongly indicate that mGluR2/3 agonists have desirable 'therapeutic' effects in animal models of aspects of cocaine dependence. However, the relative contributions of the mGluR2 and mGluR3 subtypes to the observed effects of the mGluR2/3 agonists remain unclear. Furthermore, the observed effects of mGluR2/3 agonists on both drug- and food-maintained responding remain problematic because such findings on responding for food may suggest a non-optimal side-effect profile (Mello and Negus, 1996).

Recently, relatively selective mGluR2 positive allosteric modulators (PAMs) have been developed (Johnson et al, 2003, 2005; Schaffhauser et al, 2003; Hu et al, 2004; Pinkerton et al, 2004; Bonnefous et al, 2005; Galici et al, 2005, 2006; Govek et al, 2005; Benneyworth et al, 2007). These compounds show selectivity for mGluR2 compared with other mGluR subtypes (Johnson et al, 2003, 2005; Schaffhauser et al, 2003; Galici et al, 2006) and bind at an allosteric site on the receptor to potentiate glutamateinduced activation of the receptor (Schaffhauser et al, 2003). mGluR2 PAMs have some of the same behavioral effects as mGlu2/3 agonists in animal tests used to assess anxiolytic and antipsychotic activity (Johnson et al, 2003, 2005; Schaffhauser et al, 2003; Pinkerton et al, 2004; Bonnefous et al, 2005; Galici et al, 2005, 2006; Govek et al, 2005; Benneyworth et al, 2007). These findings are consistent with recent reports showing that mGluR2, but not mGluR3, mediates the actions of the mGluR2/3 agonist LY379268 in mouse tests predictive of antipsychotic activity (Woolley et al, 2008). On the basis of the findings discussed above, we hypothesized that decreasing glutamate neurotransmission by acute administration of an mGluR2 PAM would reduce cocaine self-administration and cue-induced reinstatement of cocaine seeking, as well as cocaine-induced enhancement of brain reward function, similar to mGluR2/3 agonists. We also hypothesized that mGluR2 PAMs, because of their modulatory properties, would have specific effects on cocaine-maintained behaviors at doses that do not affect food-maintained responding. This hypothesis was supported by our previous work showing that positive modulation of $\mathrm{GABA}_{\mathrm{B}}$ receptors selectively decreased nicotine self-administration with limited effects on foodmaintained responding (Paterson et al, 2008).

The discovery and preclinical testing of highly selective mGluR2 PAMs with good brain penetration will significantly contribute to the discovery of novel therapeutic treatments for different aspects of cocaine dependence. Accordingly, we examined the effects of acute systemic administration of the mGluR2 PAM potassium $3^{\prime}-([(2-$ cyclopentyl-6-7-dimethyl-1-oxo-2,3-dihydro-1H-inden-5-yl)oxy] methyl)biphenyl 1-4-carboxylate (BINA; Galici et al, 2006; Benneyworth et al, 2007) on cocaine self-administration and cocaine seeking in rats that had short $(1 \mathrm{~h})$ or long $(6 \mathrm{~h})$ access to cocaine. For comparison purposes, we also evaluated the effects of LY379268, an mGluR2/3 agonist, on cocaine selfadministration in rats with short and long access to cocaine. In addition, we examined the effects of BINA on food-maintained responding and food-seeking behavior to assess the selectivity of BINA on cocaine- $v$ s food-maintained behavior. Finally, we examined the effects of BINA on ICSS reward thresholds under baseline conditions and on cocaine-induced reward enhancement, reflected in the ICSS procedure. Before behavioral testing, the selectivity of BINA for mGluR2 vs mGluR3 and the efficacy of BINA after systemic administration were evaluated 
using various in vitro and in vivo assays, including pharmacokinetic properties and blood-brain barrier penetration.

\section{MATERIALS AND METHODS}

\section{Subjects}

Male Wistar rats (Charles River, Raleigh, NC), weighing 300-350 g at the beginning of the experiments, were housed two per cage in a temperature- and humidity-controlled vivarium on a reversed $12 \mathrm{~h}-12 \mathrm{~h}$ light-dark cycle (lights on at $2000 \mathrm{~h}$ ). All behavioral testing took place during the dark phase of the light-dark cycle. Rats had unlimited access to water and food except during food training when food was restricted to $20 \mathrm{~g} /$ day per rat. All animals were treated in accordance with the guidelines of the National Institutes of Health regarding the principles of animal care. Animal facilities and experimental protocols were in accordance with the Association for the Assessment and Accreditation of Laboratory Animal Care.

\section{Drugs}

Cocaine hydrochloride (National Institute on Drug Abuse, Bethesda, MD) was dissolved in sterile physiological saline. Experimenter-administered cocaine was injected intraperitoneally (i.p.) in a volume of $1 \mathrm{ml} / \mathrm{kg}$, with a pretreatment time of $10 \mathrm{~min}$. The cocaine solution for intravenous self-administration was filtered through a $0.22 \mu \mathrm{m}$ syringe filter (Fisher Scientific, Pittsburgh, PA) for sterilization purposes. The mGluR2/3 agonist LY379268 ([-]-2-oxa-4-aminobicyclo[3.1.0] hexane-4,6-dicarboxylate) was custom synthesized according to the synthesis described elsewhere (Monn et al, 1999) and purchased from ANAWA (Wangen, Switzerland). LY379268 was dissolved in sterile water, $\mathrm{pH}$-adjusted to 7.4 with sodium hydroxide, and administered subcutaneously in a volume of $1 \mathrm{ml} / \mathrm{kg}$, with a pretreatment time of $30 \mathrm{~min}$, consistent with previous work with this compound (Baptista et al, 2004; Bossert et al, 2004; Liechti et al, 2007). BINA was synthesized in the laboratory of one of the authors (NC). The experimental procedures for the large-scale preparation of BINA and the spectroscopic data for BINA and the synthetic intermediates are provided in the Supplementary Materials and methods. BINA was dissolved in sterile water and administered i.p. in a volume of $5 \mathrm{ml} / \mathrm{kg}$, with a pretreatment time of $60 \mathrm{~min}$. All doses are defined as the BINA potassium salt.

\section{In Vitro Cell Culture and Thallium Flux Assays}

Human embryonic kidney (HEK-293) cell lines co-expressing rat mGluR2 or rat mGluR3 and G protein-coupled inwardly rectifying potassium (GIRK) channels (Niswender et al, 2008) were used for in vitro evaluation of compound activity through thallium flux assays. Full experimental procedures for cell culture conditions, preparation of rat mGluR2 or rat mGluR3 GIRK cell lines, and thallium flux assay protocols are provided in the Supplementary Materials and methods.

\section{Absorption, Distribution, Metabolism, and Excretion (ADME) and Pharmacokinetic Studies}

A full description of experimental procedures, evaluating BINA absorption, metabolism, and excretion as well as pharmacokinetic studies are provided in the Supplementary Materials and methods.

\section{Behavioral Procedures}

Food training and food-maintained responding. Rats were placed under food restriction ( $20 \mathrm{~g} /$ day per rat) and trained to lever press for $45 \mathrm{mg}$ food pellets (Research Diets, New Brunswick, NJ). Training started on a fixed-ratio 1 time-out $1 \mathrm{~s}$ (FR1 TO 1s) schedule of reinforcement, which then increased to FR1 TO $20 \mathrm{~s}$. Only the active lever was used during food training. Successful acquisition of the food response was defined as earning 100 pellets during a 60-min session. The training period lasted approximately 5 days. An identical training procedure was used for both the foodmaintained responding subjects and the rats that later were allowed to self-administer cocaine.

Cocaine self-administration procedure. Methodological details of catheter construction, surgery, and apparatus have been described previously (Semenova and Markou, 2003a). Rats were prepared with intravenous catheters inserted into the right jugular vein under isoflurane anesthesia (1-1.5\% isoflurane/oxygen mixture). Cocaine self-administration training began after 7 days of recovery from surgery during daily $1 \mathrm{~h}$ self-administration testing sessions. These sessions were initiated by extension of both the active and inactive levers. Responses at the active lever were reinforced under an FR1 schedule of reinforcement by an intravenous injection of cocaine $(0.5 \mathrm{mg} / \mathrm{kg}$ per infusion salt) delivered over a 2-s period in a volume of $0.05 \mathrm{ml}$. On completion of the operant response for cocaine delivery, a cue light above the lever was turned on for $20 \mathrm{~s}$ and signaled the time-out period, during which responses had no consequences. Responses at the inactive lever were recorded but had no scheduled consequences. All rats were trained to self-administer cocaine for 10 days. The criteria for showing stable performance ( $>10$ infusions per session; $<20 \%$ variation over three consecutive sessions) were reached by all rats during this 10 -day period. On day 11, two groups of rats, balanced for body weight and cocaine intake, were formed. One group of rats continued to have access to cocaine for a daily short $1 \mathrm{~h}$ (ShA) session, whereas the second group of rats had access to cocaine for a long $6 \mathrm{~h}$ (LgA) session for an additional 20 days (ie, 'escalation' phase for the LgA rats).

Extinction procedure. After completion of the 'escalation' phase of cocaine self-administration and the assessment of the effects of the various pharmacological manipulations (see below), all rats underwent 7 days of cocaine abstinence followed by seven consecutive daily extinction testing days. Similarly, rats assigned to food responding underwent seven consecutive daily extinction sessions after food training was completed; the latter took approximately 7 days. Responses at both the inactive and active lever were recorded but had no consequences (ie, no cue light illumination, no infusion/ no food, and no syringe pump activation noise). In addition, during the seven extinction sessions, rats were not attached to the tubing or the metal leads while in the operant chamber to minimize the cues associated with cocaine administration. During these seven extinction 
sessions, all rats reached the extinction criteria (ie, $<30 \%$ of baseline responding during the last two extinction sessions compared with the mean of the last 3 days of cocaine selfadministration).

Reinstatement procedure. The reinstatement phase started 1 day after the last extinction session. All conditions during the reinstatement sessions were the same as during the cocaine or food self-administration testing sessions, with the exception that responses at the active lever resulted in contingent presentation of the previously cocaine- or foodassociated cue light and the delivery of a saline infusion instead of cocaine in the cocaine group. The reinstatement session was initiated by the delivery of one noncontingent presentation of the cue light identical in all parameters to the previously presented cue light during the selfadministration phase of the experiment (ie, 20-s cue light presentation). The reinstatement session duration was $1 \mathrm{~h}$ for both cocaine- and food-responding groups. For the cocaine groups, four reinstatement sessions were conducted every third day (days 1, 4, 7, and 10 of the reinstatement phase), separated by two extinction sessions (cue and cocaine absent) to re-extinguish responding. There were two reinstatement sessions after vehicle administration: one vehicle reinstatement session was part of the Latin-square design and another vehicle reinstatement session occurred after the completion of the Latin square. This last reinstatement session after vehicle administration allowed us to assess the persistence of the reinstatement effect and the feasibility of using a within-subjects design for the cocaine studies. The food-responding rats had a single reinstatement test session because a between-subjects design for the factor drug dose was used (see below).

ICSS procedure. Methodological details of surgery, apparatus, and the ICSS procedure are described in detail elsewhere (Markou and Koob, 1992; Harrison et al, 2002; Semenova and Markou, 2003b), as well as in the Supplementary Materials and methods. Briefly, subjects were prepared with stainless steel bipolar electrodes in the posterior lateral hypothalamus (anterior/posterior, $-0.5 \mathrm{~mm}$ from bregma; medial/lateral, $\pm 1.7 \mathrm{~mm}$; dorsal/ventral, $-8.3 \mathrm{~mm}$ from dura; incisor bar set $5 \mathrm{~mm}$ above the interaural line; Pellegrino et $a l, 1986)$ under isoflurane/oxygen vapor mixture (1-1.5\% isoflurane) anesthesia. Subjects were trained to respond for electrical stimulation under a discrete-trial current-threshold ICSS procedure, modified from Kornetsky et al (1979). Each test session typically lasted $30-40 \mathrm{~min}$ and provided two dependent variables for behavioral assessment: threshold and response latency (Markou and Koob, 1992; Harrison et al, 2002; Semenova and Markou, 2003b).

\section{Behavioral Experimental Designs}

Experiment 1: effects of BINA and LY379268 on cocaine self-administration and food-maintained responding. After completion of the 'escalation' phase of cocaine selfadministration, drug treatments were initiated. BINA and LY379268 were administered according to two sequential within-subjects Latin-square designs. First, BINA (0, 10, 20 , and $40 \mathrm{mg} / \mathrm{kg}$, i.p.; $60 \mathrm{~min}$ pretreatment time) was administered to ShA $(n=12)$ and LgA $(n=15)$ groups. One rat from the LgA group initially showed unstable performance and was not included in the BINA experiment, but this rat established stable performance at a later time-point and was included in the LY379268 experiment. After completion of the BINA experiment, the catheters of four LgA rats lost patency, and these subjects were excluded from the LY379268 experiment. After completion of the BINA experiment, the ShA $(n=12)$ and $\operatorname{LgA}(n=12)$ rats were treated with $0,0.3,1$, and $3 \mathrm{mg} / \mathrm{kg}$ LY379268 (i.p.) $30 \mathrm{~min}$ before testing. The highest LY379268 dose $(6 \mathrm{mg} / \mathrm{kg})$ was administered to all rats after completion of the Latin square. At least 3 days elapsed between drug/vehicle injections to re-establish stable self-administration behavior ( $<20 \%$ variation over 3 days).

To assess possible nonspecific actions of BINA and LY379268, the effects of BINA $(0,10,20$, and $40 \mathrm{mg} / \mathrm{kg}$, i.p.) and $\operatorname{LY} 379268(0,0.3,1,3$, and $6 \mathrm{mg} / \mathrm{kg}$, i.p.) were also assessed in animals trained to lever press for food during 1 -h sessions. The FR1 TO $20 \mathrm{~s}$ schedule of reinforcement used for food-maintained responding was identical in all parameters to the schedule under which cocaine was selfadministered.

Experiment 2: effects of BINA on cue-induced reinstatement of cocaine- or food-seeking behavior. Rats from experiment 1 were also used to analyze the effects of BINA on the reinstatement of extinguished cocaine self-administration. After completion of the two sequential Latin squares with BINA and LY379268 administration (experiment 1), LgA $(n=13)$ and ShA $(n=12)$ rats underwent 7 days of abstinence from cocaine self-administration with no handling or behavioral testing. Starting on day 8 of cocaine abstinence, rats underwent extinction training during seven 1-h daily extinction testing sessions, as described above. Four doses of BINA $(0,10,20$, and $40 \mathrm{mg} / \mathrm{kg})$ were injected $60 \mathrm{~min}$ before each 1 -h reinstatement test session according to a within-subjects Latin-square design.

To assess possible nonspecific actions of BINA, the effects of BINA were also assessed on food-seeking behavior. A between-subjects design was used because cue-induced food-seeking behavior shows rapid extinction with repeated reinstatement testing, prohibiting the use of a withinsubjects design (Bespalov et al, 2005). Thus, four independent groups of naive rats ( $n=10$ per group) responding for food were tested with different doses of BINA $(0,10,20$, and $40 \mathrm{mg} / \mathrm{kg}$, i.p.) in a single reinstatement test session after a 7-day extinction period. Cue-induced responding was calculated as the total number of responses emitted on the active lever, including the responses emitted during the 20-s time-out period when the cue light was presented.

Experiment 3: effects of BINA administration on brain reward function and cocaine-induced reward enhancement. Naive rats $(n=11)$ were prepared with ICSS electrodes and trained in the ICSS procedure. After establishment of stable ICSS thresholds, the effects of BINA alone and combined with cocaine on thresholds and response latencies were assessed according to two sequential Latin-square designs. First, BINA $(0,10,20$, and $40 \mathrm{mg} / \mathrm{kg}$, i.p., $60 \mathrm{~min}$ pretreatment time) was administered under baseline conditions with at least 3 days between each BINA administration, during which time rats were tested in the 
ICSS procedure without treatment. The same rats then received BINA $(0,10,20$, and $40 \mathrm{mg} / \mathrm{kg}$, i.p., $60 \mathrm{~min}$ pretreatment time) combined with cocaine $(10 \mathrm{mg} / \mathrm{kg}$, i.p., $10 \mathrm{~min}$ pretreatment time) according to a Latin-square design. Our previous studies have shown that cocaine at a dose of $10 \mathrm{mg} / \mathrm{kg}$ induced maximal threshold lowering without affecting the rats' performance in the ICSS procedure (Markou and Koob, 1992).

\section{Statistical Analyses}

Quantification of BINA in plasma and brain samples was accomplished by comparison with a standard curve created using Shimadzu LabSolutions software and Microsoft Excel. Pharmacokinetic parameters were determined by noncompartmental analysis using PK Solutions version 2.0 software (Summit Research Services). Statistical analyses of the behavioral experiments were conducted using the Statistical Package for the Social Sciences version 15.0 (SPSS, Chicago, IL).

Intravenous self-administration and food-maintained responding data were expressed as a percentage of the baseline number of rewards earned, with baseline defined as the mean number of rewards earned over the 3 days before each drug testing session. Percent values are presented to allow for direct comparisons of data between ShA and LgA groups, as well as for data derived from the two different reinforcers (ie, cocaine and food). ICSS data are expressed as a percentage of baseline, with baseline defined as the mean ICSS thresholds or latencies obtained over the 3 days before each drug testing session. To analyze the changes in cocaine intake during the escalation period, a two-way repeated-measures analysis of variance (ANOVA) was used, with Cocaine Access as the between-subjects factor and Session as the within-subjects factor. Acute effects of BINA and LY379268 on cocaine self-administration and foodmaintained responding were analyzed separately for each drug and reinforcer using two-way repeated-measures ANOVA, with Dose as the within-subjects factor and Cocaine Access as the between-subjects factor. Cocaineand food-seeking data are expressed as the mean number of lever presses \pm SEM during reinstatement sessions. The subgroups of reinstated and non-reinstated rats were determined based on both a median split analysis and a predefined criterion (ie, the absolute number of active lever presses during both reinstatement sessions after vehicle administration being larger than the mean number of active lever presses during the last 2 days of extinction). ANOVAs with Dose as either the within-subjects factor (for cocaineseeking data) or between-subjects factor (for food-seeking data) were used to analyze the effects of BINA on cueinduced reinstatement of cocaine- and food-seeking behavior, respectively. Acute effects of BINA on ICSS baseline performance and cocaine-induced thresholds/latencies were analyzed using two-way repeated-measures ANOVA, with BINA and Cocaine as within-subject factors. Post hoc comparisons were conducted with least significant difference (LSD) tests. To test the a priori hypothesis relating to the differential effects of BINA and LY379268 on cocaine intake in the ShA and LgA groups, comparisons were made using unpaired $t$-tests, in addition to the post hoc tests, after statistically significant effects in the ANOVAs. The criterion for significance was set at the 0.05 level.

\section{RESULTS}

\section{In Vitro mGluR Assays}

We recently developed a novel assay that takes advantage of the ability of the $\beta \gamma$ subunits of $\mathrm{G}_{\mathrm{i}}$ and $\mathrm{G}_{\mathrm{o}}$ heterotrimers to interact with G-protein-coupled inwardly rectifying potassium (GIRK) channels, which leads to alterations in the kinetics of channel opening (Niswender et al, 2008). This assay exploits the ability of potassium channels to conduct thallium ions $\left(\mathrm{Tl}^{+}\right)$(Weaver et al, 2004). Using this assay, we examined the regulation of heteromeric GIRK 1/2 channels by endogenous and transfected $G_{i / o}$-coupled $G$ protein-coupled receptors (GPCRs). We found that each of the group III mGluRs (mGluRs 4, 7, and 8) coupled to the modulation of GIRK current and that thallium flux through GIRK channels provides a sensitive and high-throughput screening method to examine the $\beta \gamma$-mediated signaling properties of agonists, antagonists, and allosteric modulators of various $\mathrm{G}_{\mathrm{i} / \mathrm{o}}$-linked GPCRs (Niswender et al, 2008). The majority of studies developing positive and negative mGluR2 allosteric modulators employ as their functional readout either forced coupling to chimeric G-proteins, such as $\mathrm{G}_{\mathrm{qi} 5}$, to measure a calcium response downstream of mGluR2 or GTP $\gamma$ S binding assays to detect functional activity of mGluR3 (Galici et al, 2006; Hemstapat et al, 2007). However, these assays, particularly the GTP $\gamma S$ binding assay used for mGluR3, are not readily amenable to the high-throughput screening that is needed for detailed pharmacological analysis and new ligand discovery.

Given the robust coupling of group III mGluRs to modulation of GIRK current, we evaluated the ability of group II mGluRs to couple to GIRK channels in this assay. As we previously showed with group III mGluRs (Niswender et al, 2008), we found that group II mGluRs readily couple to heteromeric GIRK channels in HEK-293 cells (Figure 1a). Glutamate induced a concentration-dependent increase in thallium flux with an $\mathrm{EC}_{50}$ of $849 \pm 64 \mathrm{nM}$ for mGluR2 and $565 \pm 19 \mathrm{nM}$ for mGluR3. To verify that GIRK channel modulation occurs through a group II mGluR, the mGluR2/3 orthosteric antagonist LY341495 (Johnson et al, 1999) was evaluated in the thallium flux assay. LY341495 potently inhibited the $\mathrm{EC}_{80}$ glutamate response at both mGluR2 and mGluR3 GIRK cells in a thallium flux assay, with an $\mathrm{IC}_{50}$ of $26.1 \pm 0.7 \mathrm{nM}$ for mGluR2 GIRK and $7.1 \pm 0.4 \mathrm{nM}$ for mGluR3 GIRK (Figure 1b). Having established mGluR2 GIRK and mGluR3 GIRK functional assays, we next evaluated the mGluR2 PAM BINA in this assay and verified its activity as a PAM toward mGluR2 (Figure 1c). BINA induced a concentration-dependent increase in the $\mathrm{EC}_{20}$ glutamate response toward mGluR2 GIRK with an $\mathrm{EC}_{50}$ of $347.6 \pm 51.4 \mathrm{nM}$ and was inactive toward mGluR3 (Figure 1c), as previously described (Galici et al, 2006). These in vitro studies established the activity of our scale-up synthesis of BINA and provide a platform for future mGluR2 and mGluR3 drug discovery efforts.

\section{ADME and Pharmacokinetic Studies In Vitro and In Vivo}

As a precursor to in vivo efficacy studies, we first evaluated BINA in a set of in vitro ADME assays and then performed in vivo pharmacokinetic studies to determine BINA drug 
levels in plasma and brain after systemic administration in rats. Thus, we used rat microsomal and rat plasma stability assays to determine the likely extent of first-pass metabolism of BINA after administration in rats. We also evaluated BINA in an in vitro parallel artificial membrane permeation assay to assess gastrointestinal absorption and blood-brain barrier permeability using specific central nervous system membrane lipids. The BINA profile in these assays is shown in Table 1. The data suggest that BINA has a promising in vitro ADME profile, including resistance to microsomal degradation and plasma enzyme metabolism, as well as very good potential for blood-brain barrier
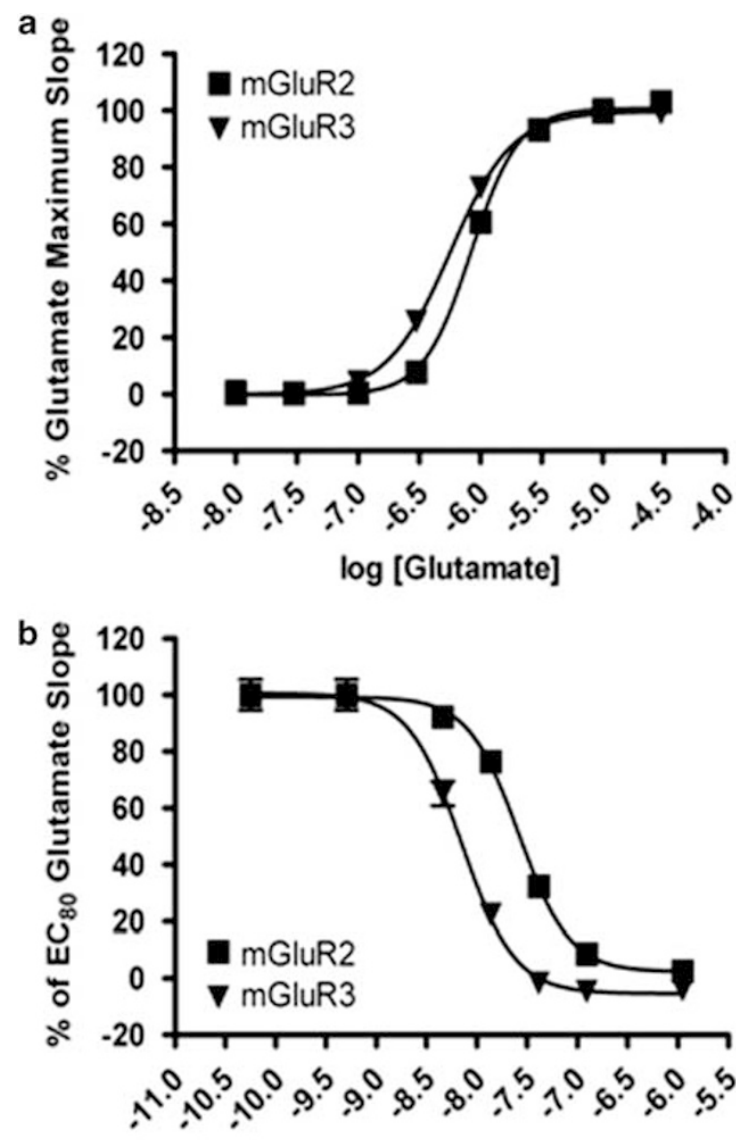

$\log$ [LY341495]

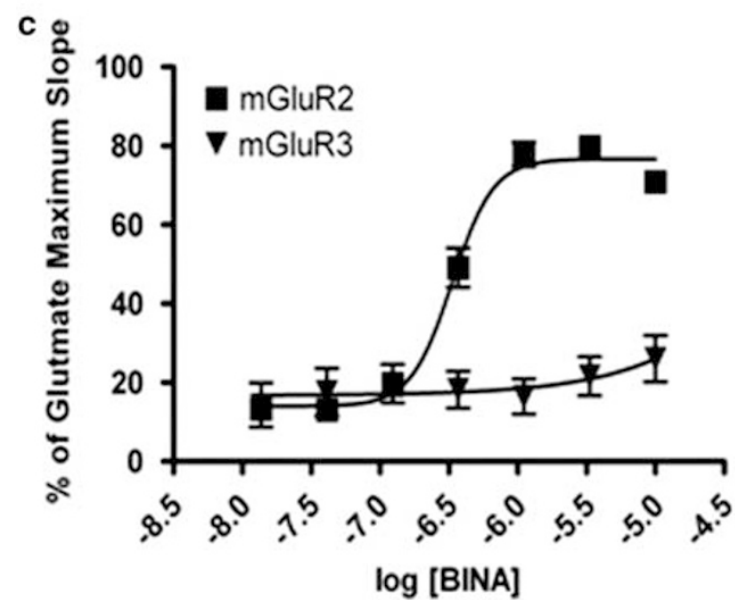

permeability. We also assessed the plasma levels and central nervous system penetration of BINA by direct measurement of brain drug levels because brain penetration is a key determinant of both systemic activity and therapeutic efficacy for mGluR2 PAMs. The in vivo pharmacokinetic data for BINA are shown in Tables 2 and 3, indicating that BINA achieved excellent plasma and brain levels after systemic (i.p.) administration in Wistar rats. The pharmacokinetic data were used to guide the selection of doses and time-points for data collection for the determination of the in vivo efficacy of BINA in the behavioral experiments.

\section{Behavioral Experiments}

No effects of dose order on cocaine self-administration, reinstatement, or ICSS data (threshold and latency) were revealed by ANOVA analyses for any of the experiments (data not shown).

Table I BINA Characteristics Using In Vitro Assays

\begin{tabular}{|c|c|c|c|c|}
\hline \multirow{2}{*}{$\begin{array}{l}\text { Metabolic } \\
\text { stability } \\
\text { (\% remaining } \\
30 \text { min) }\end{array}$} & \multirow{2}{*}{$\begin{array}{c}\text { Plasma } \\
\text { stability } \\
\text { (\% remaining } \\
30 \mathrm{~min})\end{array}$} & \multicolumn{2}{|c|}{ Permeability-PAMPA ${ }^{a}$} & \multirow[t]{2}{*}{$\begin{array}{l}\text { Verapamil } \\
\text { (BBB, GI) }\end{array}$} \\
\hline & & $\begin{array}{l}\text { PAMPA } \\
\text { (BBB) }\end{array}$ & $\begin{array}{l}\text { PAMPA } \\
\text { (GI) }\end{array}$ & \\
\hline 19 & 81 & -6.1 & -5.7 & $-4.7,-3.05$ \\
\hline
\end{tabular}

Abbreviations: BBB, blood-brain barrier; Gl, gastrointestinal; PAMPA, parallel artificial membrane permeation assay.

${ }^{a}$ Verapamil was used as a highly permeable standard.

Table 2 BINA Pharmacokinetic Parameters After i.p. Administration in Rats

\begin{tabular}{lccccr}
\hline $\begin{array}{l}\text { Dose } \\
(\mathbf{m g} / \mathbf{k g})\end{array}$ & $\mathbf{t}_{\mathbf{1 / 2}} \mathbf{( h )}$ & $\begin{array}{c}\mathbf{C}_{\max } \\
(\boldsymbol{\mu} \mathbf{M} / \mathbf{l})\end{array}$ & $\begin{array}{c}\text { AUC } \\
(\mathbf{h} \boldsymbol{\mu M / l )})\end{array}$ & $\mathbf{V d}(\mathbf{I} / \mathbf{k g})$ & $\mathbf{C l}(\mathbf{I} / \mathbf{h})$ \\
\hline 20 & $4.6 \pm 1.8$ & $9.3 \pm 2.7$ & $31 \pm 5.0$ & $5.9 \pm 2.6$ & $1.3 \pm 0.21$ \\
40 & $1.8 \pm 0.63$ & $31 \pm 14$ & $114 \pm 42$ & $1.7 \pm 0.68$ & $0.78 \pm 0.29$ \\
\hline
\end{tabular}

Data are expressed as mean $\pm S D . n=3$ (number of samples per dose).

Figure I In vitro profiling of mGluR2 and mGluR3 GIRK thallium flux assays shows that BINA has mGluR2 selective PAM activity. (a) Concentration response curves (CRCs) of glutamate were performed on HEK-293 cells expressing heteromeric GIRK channels and either mGluR2 (mGluR2 GIRK) or mGluR3 (mGluR3 GIRK) in a thallium flux assay. Data are expressed as the percentage of the maximal glutamate response. $E_{50}$ values for glutamate were $849 \pm 64 \mathrm{nM}$ for mGluR2 and $565 \pm 19 \mathrm{nM}$ for mGluR3. (b) CRCs of LY34I495 were performed in the presence of an $\mathrm{EC}_{80}$ concentration of glutamate on mGluR2 GIRK or mGluR3 GIRK cells in a thallium flux assay. Data are expressed as the percentage of the glutamate $E_{80}$. IC 50 values for LY34I 495 inhibition were $26.1 \pm 0.7 \mathrm{nM}$ for mGluR2 GIRK and $7.1 \pm 0.4 \mathrm{nM}$ for mGluR3 GIRK. (c) CRCs of BINA were performed in the presence of an $\mathrm{EC}_{20}$ concentration of glutamate on mGluR2 GIRK of mGluR3 GIRK cells in a thallium flux assay. The EC 50 for BINA's potentiation of the glutamate $\mathrm{EC}_{20}$ was $347.6 \pm 51.4 \mathrm{nM}$ for mGluR2 GIRK. BINA was inactive for potentiation of the glutamate $\mathrm{EC}_{20}$ for mGluR3 GIRK. All data are expressed as the mean of a minimum of three independent experiments performed in triplicate, and error bars represent SEM. 
Table 3 BINA Brain/Plasma Concentrations

\begin{tabular}{lccc}
\hline $\begin{array}{l}\text { Dose } \\
(\mathbf{m g} / \mathbf{k g})\end{array}$ & $\begin{array}{c}\text { Brain level } \\
(\mathbf{m e a n}, \boldsymbol{\mu} \mathbf{M})^{\mathbf{a}}\end{array}$ & $\begin{array}{c}\text { Plasma level } \\
(\mathbf{m e a n}, \boldsymbol{\mu M})^{\mathbf{a}}\end{array}$ & $\begin{array}{c}\text { Brain/Plasma } \\
\text { ratio (mean) }\end{array}$ \\
\hline 20 & $2.78(0.65-6.39)$ & $10.54(0.79-25.48)$ & 0.47 \\
40 & $2.30(0.62-5.54)$ & $7.79(0.81-16.98)$ & 0.44 \\
\hline
\end{tabular}

${ }^{\mathrm{a} B r a i n}$ and plasma concentration data are expressed as the geometric mean followed in parentheses by the lower and upper limits of the mean. $n=5$ (number of samples per dose).

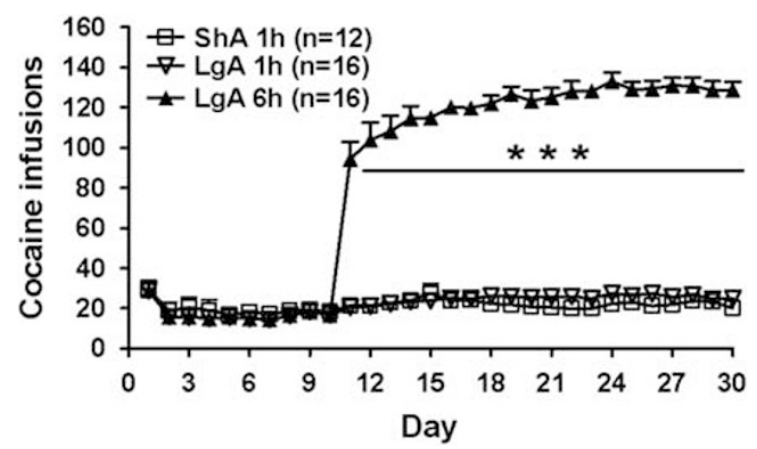

Figure 2 Acquisition of cocaine self-administration under short (ShA, I-h session) and long (LgA, 6-h session) access conditions. The graph shows the number of infusions (mean \pm SEM) earned by the ShA and LgA groups during the initial 10 days of acquisition of cocaine self-administration and the subsequent 20 days when LgA rats had access to cocaine for $6 \mathrm{~h}$ per day, whereas ShA rats continued to have access for I h per day. The number of cocaine infusions earned are shown for the I-h session for ShA rats for the 30 days of testing and for the entire 6-h session for LgA rats from day 20 onward, as well as for the first hour of the 6-h session for LgA rats. $*^{*} * x<0.001$, significant escalation of cocaine self-administration compared with day 10 in LgA rats.

Experiment 1: effects of BINA and LY379268 on cocaine self-administration and food-maintained responding. The number of cocaine infusions during acquisition of cocaine self-administration in ShA and LgA rats and escalation of cocaine self-administration in LgA rats are presented in Figure 2. Both ShA and LgA rats acquired stable cocaine self-administration (ie, number of cocaine infusions earned) during the initial 10 days of 1 -h self-administration sessions. During the subsequent testing phase, ShA rats continued to show stable cocaine intake (ie, number of cocaine infusions earned) during their 1-h testing sessions $\left(\mathrm{F}_{19,209}=1.3\right.$, n.s. $)$, whereas LgA rats progressively increased their cocaine intake during the 'escalation phase' (ie, when they had access to cocaine for $6 \mathrm{~h}$ per day) from $94.25 \pm 8.64$ infusions on day 1 of the 'escalation phase' to $128.75 \pm 3.99$ infusions on day 20 of the 'escalation phase' $\left(\mathrm{F}_{19,285}=6.18, p<0.001\right)$ (Figure 2$)$. LSD post hoc tests revealed that, starting from the third 6-h session onward, cocaine intake was significantly increased above the level of the first 6-h session in LgA rats. Similar escalation of cocaine intake in $\operatorname{LgA}$ rats was observed during the first hour of the 6-h self-administration session $\left(\mathrm{F}_{19,285}=2.17\right.$, $p<0.01$ ).

In ShA rats in the BINA and LY379268 experiments, the numbers of baseline cocaine infusions earned were
$21.01 \pm 1.9$ and $18.07 \pm 1.28$ (mean \pm SEM) before each of the two experiments, respectively. In LgA rats in the BINA and LY379268 experiments, the numbers of baseline cocaine infusions earned were $129.79 \pm 3.92$ and $136.06 \pm 5.82$ (mean \pm SEM) for each of the two experiments, respectively. One-way ANOVAs on the number of baseline cocaine infusions during the 3 baseline days before the drug treatment days indicated no significant differences, showing the stability of baseline self-administration in both ShA and $\operatorname{LgA}$ rats during the experiment (data not shown).

Systemic BINA administration significantly decreased cocaine self-administration in both ShA and $\operatorname{LgA}$ rats during the first hour of the session (Figure 3a) and during the entire 6-h session in LgA rats (Figure 3b). An overall two-way ANOVA that included data from ShA rats (1-h session) and $\operatorname{LgA}$ rats (6-h session) revealed main effects for the factors Cocaine Access $\left(\mathrm{F}_{1,25}=15.72, p<0.01\right)$ and BINA Dose $\left(\mathrm{F}_{3,75}=44.94, p<0.01\right)$ but no Cocaine Access $\times$ BINA Dose interaction. On the basis of our a priori hypothesis that the effects of BINA would be different in ShA and LgA rats, we conducted separate ANOVAs on data from the ShA and LgA rats. ANOVA analyses revealed a significant effect of BINA Dose in both ShA $\left(\mathrm{F}_{3,47}=29.54\right.$, $p<0.0001)$ and $\operatorname{LgA}\left(\mathrm{F}_{3,59}=9.98, p<0.0001\right)$ rats. LSD post hoc tests after separate ANOVA analyses on data from ShA and LgA rats showed a significant decrease in cocaine intake after BINA administration at the doses of $20 \mathrm{mg} / \mathrm{kg}$ $(p<0.05)$ and $40 \mathrm{mg} / \mathrm{kg}(p<0.01)$ in both ShA and LgA rats compared with the corresponding vehicle treatment condition. When comparing cocaine intake (ie, number of infusions earned) during the first hour of the session in ShA and LgA rats, a two-way ANOVA revealed a main effect of BINA Dose $\left(\mathrm{F}_{3,75}=29.52, p<0.01\right)$ and Cocaine Access $\left(\mathrm{F}_{1,25}=4.76, p<0.05\right)$, but no BINA Dose $\times$ Cocaine Access interaction. LSD post hoc tests after the separate ANOVA analyses on data from ShA (BINA Dose: $\mathrm{F}_{3,47}=29.54$, $p<0.0001)$ and LgA (BINA Dose: $\left.\mathrm{F}_{3,59}=6.27, p<0.001\right)$ rats again showed a significant decrease in cocaine intake after BINA administration at the doses of 20 and $40 \mathrm{mg} / \mathrm{kg}$ in ShA and LgA rats $(p<0.05)$ compared with the corresponding vehicle treatment condition. In addition, the magnitude of the effects of BINA on cocaine intake was larger in ShA compared with $\operatorname{LgA}$ at the doses of 20 and $40 \mathrm{mg} / \mathrm{kg}$ $(p<0.05$, unpaired $t$-test, Figure 3a). BINA had no effect on inactive lever presses at any of the doses tested (data not shown). BINA administration had no effect on food responding (Figure 3a).

Systemic LY379268 administration also significantly decreased cocaine self-administration in both ShA and $\operatorname{LgA}$ rats during the first hour of the session (Figure $3 \mathrm{c}$ ) and during the entire 6-h session in LgA rats (Figure 3d). An overall two-way ANOVA that included data from ShA (1-h session) and LgA (6-h session) rats revealed a main effect of LY379268 Dose $\left(\mathrm{F}_{4,88}=28.34, p<0.01\right)$, but no main effect of Cocaine Access and no LY379268 Dose $\times$ Cocaine Access interaction. On the basis of our a priori hypothesis that the effects of LY379268 would be different in ShA and LgA rats, we conducted separate ANOVAs on data from the ShA and $\operatorname{LgA}$ rats. ANOVA analyses revealed a significant effect of LY379268 Dose in both ShA $\left(\mathrm{F}_{4,59}=12.39, p<0.0001\right)$ and $\operatorname{LgA}\left(\mathrm{F}_{4,59}=13.32, p<0.0001\right)$ rats. LSD post hoc tests after the separate ANOVA analyses on data from ShA and 


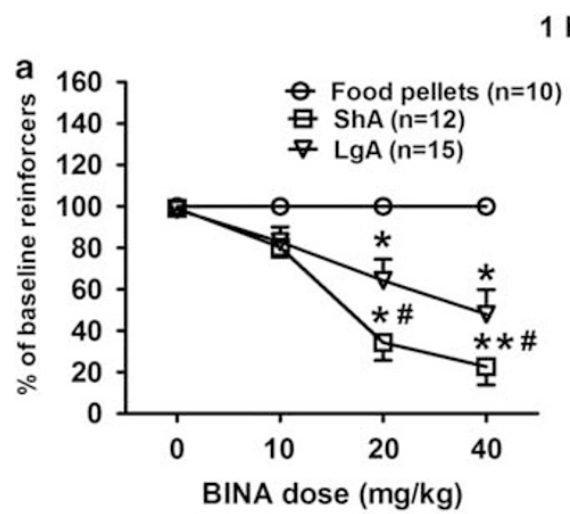

$1 \mathrm{~h}$ session
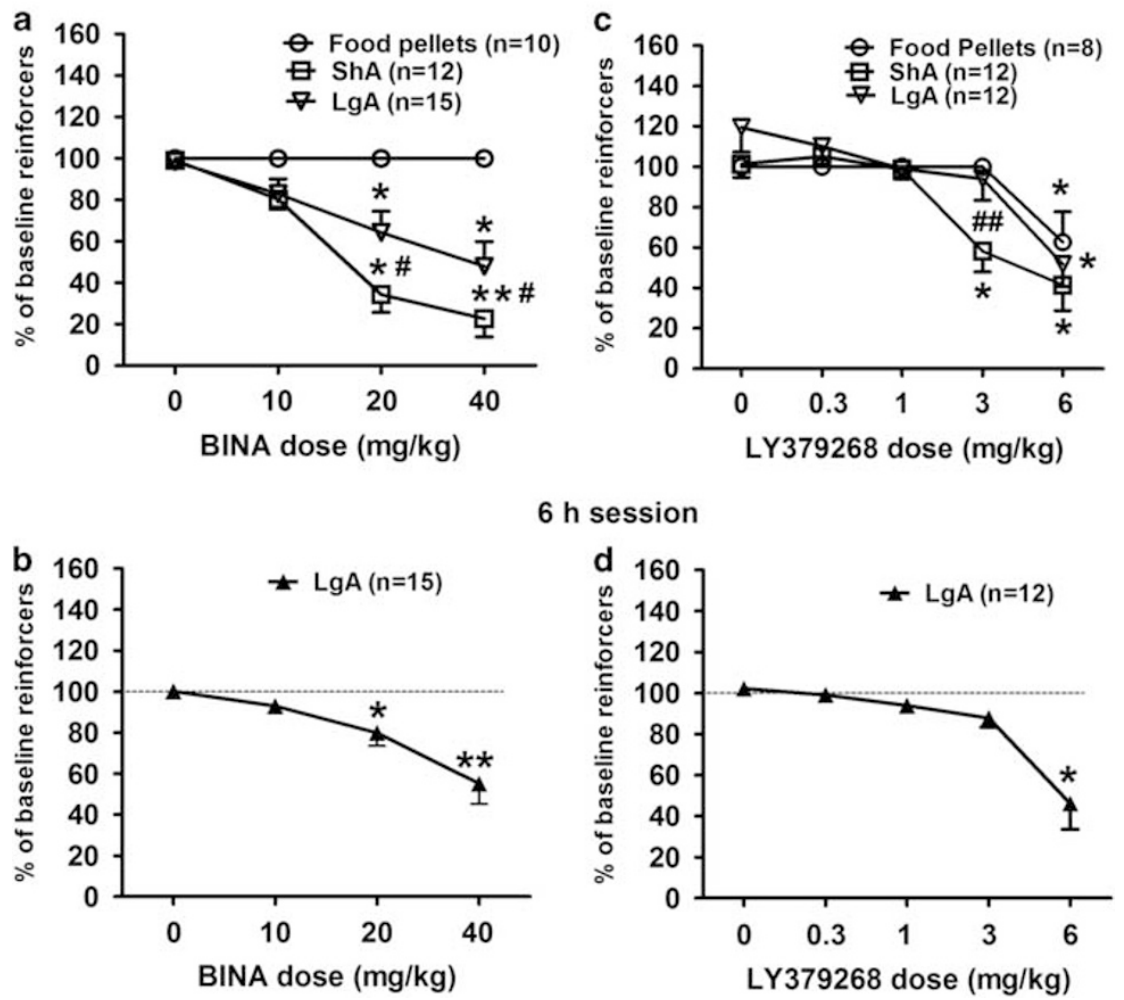

Figure 3 The effects of the mGluR2 PAM BINA and the mGluR2/3 agonist LY379268 on cocaine- and food-maintained responding in rats. BINA significantly decreased cocaine self-administration in both ShA and LgA rats (a, b) but not food-maintained responding (a). LY379268 decreased cocaine selfadministration in both ShA and LgA rats (c, d) and decreased food-maintained responding (c). Data are expressed as a percentage of baseline responding (mean \pm SEM; see text for baseline values). $* p<0.05$, ** $p<0.01$, significant differences from the corresponding vehicle condition (LSD post hoc test). ${ }^{\#} p<0.05,{ }^{\# \#} p<0.01$, significant differences between ShA and LgA rats in cocaine intake after treatment with the same dose of BINA or LY379268 (unpaired t-test).

LgA rats showed a significant decrease in cocaine intake when LY379268 was administered at doses of 3 and $6 \mathrm{mg} / \mathrm{kg}$ in ShA rats $(p<0.05)$ and $6 \mathrm{mg} / \mathrm{kg}$ in $\operatorname{LgA}$ rats $(p<0.05)$. When comparing cocaine intake during the first hour of the session in ShA and LgA rats, a two-way ANOVA revealed a main effect of LY379268 Dose $\left(\mathrm{F}_{4,88}=22.61, p<0.01\right)$, but no main effect of Cocaine Access and no LY379268 Dose $\times$ Cocaine Access interaction. LSD post hoc tests after separate ANOVA analyses on data from ShA (LY379268 Dose: $\left.F_{4,59}=12.39, p<0.0001\right)$ and LgA (LY379268 Dose: $\left.F_{4,59}=6.83, p<0.001\right)$ rats again showed a significant decrease in cocaine intake after LY379268 administration at doses of 3 and $6 \mathrm{mg} / \mathrm{kg}$ in ShA rats $(p<0.05)$ and $6 \mathrm{mg} / \mathrm{kg}$ in $\operatorname{LgA}$ rats $(p<0.05)$. Group comparisons revealed that there was a significant difference in cocaine intake between LgA and ShA after LY379268 administration at the dose of $3 \mathrm{mg} / \mathrm{kg}(p<0.01$, unpaired $t$-test, Figure $3 \mathrm{c})$. A significant effect of LY379268 administration was found on responding for food $\left(\mathrm{F}_{4,39}=6.988, p<0.05\right.$, Figure $\left.3 \mathrm{c}\right)$. Post hoc analyses have shown that LY379268 significantly decreased food responding at the dose of $6 \mathrm{mg} / \mathrm{kg}(p<0.05)$. LY379268 had no effect on inactive lever presses at any of the doses tested (data not shown).

Experiment 2: effects of BINA administration on cueinduced reinstatement of cocaine- and food-seeking behavior. The total number of active lever presses was decreased significantly during the cocaine- and cue-absent extinction sessions (Figure 4a). A two-way ANOVA revealed a main effect of Extinction Day $\left(\mathrm{F}_{6,138}=18.34, p<0.05\right)$ but no main effect of Cocaine Access and no Extinction Day $\times$ Cocaine Access interaction. Both LgA and ShA rats significantly decreased their responding on days 2 through 7 of the extinction phase (LSD test, $p<0.001$ for all comparisons, Figure 4a).

To assess the stability of cue-induced cocaine-seeking behavior in the within-subject experimental design used for the assessment of the effects of different doses of the compound, two reinstatement sessions after vehicle administration were implemented (see Experimental Design and Statistical Analyses sections above for details; briefly, one vehicle session was conducted as part of the Latin-square design and one after the completion of the Latin-square design). There were no significant differences in the number of active lever presses during these two vehicle reinstatement sessions in either ShA $(8.75 \pm 2.23$ and $6.75 \pm 2.07)$ or $\operatorname{LgA}(16.62 \pm 2.9$ and $14.69 \pm 2.67)$ rats, indicating stable cocaine-seeking behavior after repeated reinstatement testing. Visual inspection of the data indicated that among both ShA and LgA rats there were subjects that did not reinstate cocaine-seeking after vehicle administration. Therefore, a median split analysis was implemented to identify subgroups of rats that reinstated or not reinstated cocaine-seeking behavior. In the subsets of ShA $(n=6)$ and 


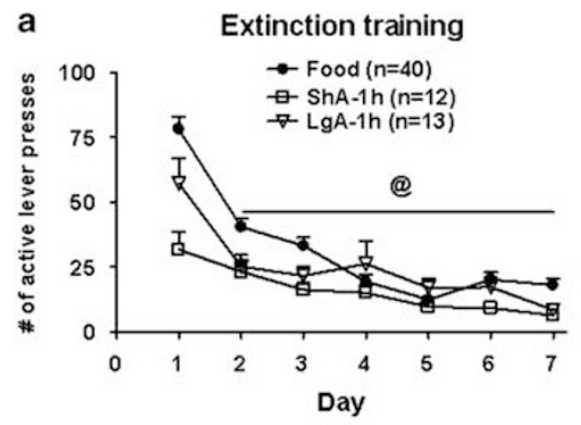

b

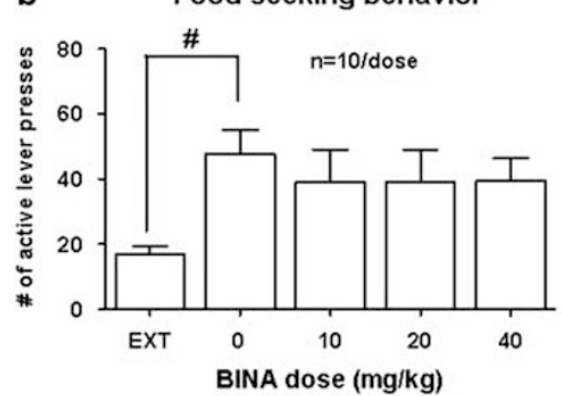

C Cocaine seeking behavior in LgA rats

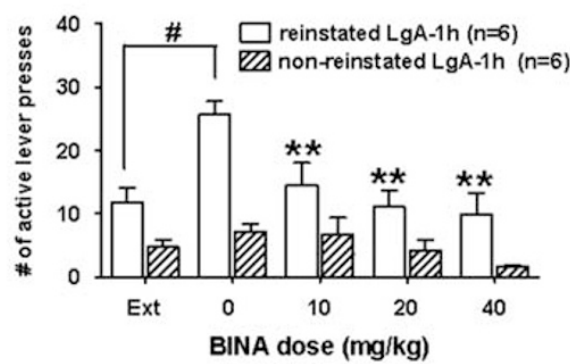

d Cocaine seeking behavior in ShA rats

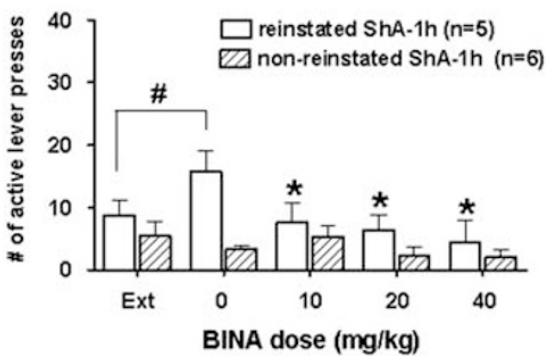

Figure 4 Effects of BINA on cue-induced reinstatement of cocaine- and food-seeking behavior. (a) The number of lever presses of ShA rats, LgA rats, and food-responding rats during I-h daily extinction sessions. (b) BINA had no effect on food seeking in food-restricted rats. BINA blocked cocaine-seeking behavior in LgA (c) and ShA (d) rats during cue-induced reinstatement sessions. Data are expressed as the mean number of lever presses \pm SEM in subsets of $\mathrm{LgA}$ and ShA rats that showed and did not show reinstatement (ie, reinstated and non-reinstated rats, respectively, based on a median split analysis; see text for details). ${ }^{*} p<0.05$, ${ }^{* *} p<0.0$ l, significant differences from $0 \mathrm{mg} / \mathrm{kg} B \mathrm{BINA} ;{ }^{\#} p<0.05$, significant difference from extinction conditions (Ext). ${ }^{@} p<0.05$, significant difference from the first day of extinction in ShA rats, LgA rats, and food-responding rats.

LgA $(n=6)$ rats that showed a number of active lever presses during the first vehicle reinstatement session below the median value, the number of active lever presses during this first vehicle reinstatement session did not differ significantly from the 2-day mean of active lever presses during the mean of the last 2 days of extinction (ShA rats: $3.33 \pm$ 0.46 and $5.42 \pm 2.34$; LgA rats: $7 \pm 1.44$ and $4.75 \pm 1.16$, respectively) indicating that these rats did not show cueinduced reinstatement of cocaine seeking. Subsequent ANOVAs showed no effect of BINA treatment $\left(\mathrm{F}_{3,23}=1.58\right.$, n.s. and $\mathrm{F}_{3,23}=3.02$, n.s., respectively) in these subgroups of ShA and LgA rats. In subsets of ShA $(n=5)$ and $\operatorname{LgA}(n=6)$ rats that showed a number of active lever presses during the first vehicle reinstatement session above the median value, the number of active lever presses during the vehicle reinstatement session were significantly $(p<0.05)$ higher compared with active lever presses during the mean of the last 2 days of extinction (ShA rats: $15.80 \pm 3.19$ and $8.73 \pm 2.48$; LgA rats: $25.67 \pm 2.05$ and $11.67 \pm 2.43$, respectively) indicating that these rats showed cue-induced reinstatement of cocaine seeking (Figures $4 \mathrm{c}$ and d). Subsequent ANOVAs indicated a significant effect of BINA treatment in these subsets of ShA and $\operatorname{LgA}$ rats $\left(\mathrm{F}_{3,19}=5.25, p<0.05\right.$ and $\mathrm{F}_{3,23}=8.6, p<0.01$, respectively). Post hoc analyses revealed that BINA significantly reduced cue-induced reinstatement of cocaine seeking in both ShA $(p<0.05)$ and $\operatorname{LgA}(p<0.01)$ rats at all doses used (Figures $4 \mathrm{c}$ and $\mathrm{d}$ ).

To more fully examine the effects of the test compounds on subgroups of rats that reinstated and did not reinstate cocaine seeking, subgroups were also determined based on an additional criterion. This criterion for reinstatement was that the absolute number of active lever presses during both reinstatement sessions after vehicle administration was larger than the mean number of active lever presses during the last 2 days of extinction. According to these analyses, only three out of the $12 \mathrm{ShA}$ rats showed cue-induced reinstatement of cocaine-seeking behavior. In these three ShA rats, BINA tended to reduce cue-induced reinstatement (data not shown). By contrast, eight of the $13 \mathrm{LgA}$ rats showed cue-induced reinstatement of cocaine-seeking behavior after vehicle administration. In these eight $\operatorname{LgA}$ rats, BINA significantly reduced cue-induced reinstatement of cocaine-seeking behavior $\left(\mathrm{F}_{3,21}=6.40, p<0.01\right)$ at the doses of 20 and $40 \mathrm{mg} / \mathrm{kg}$ compared with the vehicle condition (data not shown).

The total number of active lever presses was also decreased significantly during the food- and cue-absent extinction sessions in the food group (main effect of Extinction Day: $\mathrm{F}_{6,234}=70.64, p<0.05$, Figure $\left.4 \mathrm{a}\right)$. Responding for food was significantly decreased on days 2 through 7 of the extinction phase (LSD test, $p<0.001$ for all comparisons, Figure 4a). All food-responding rats reinstated during the cue-induced reinstatement session. During subsequent reinstatement testing, presentation of the cue light associated with food delivery reinstated foodseeking behavior after vehicle administration (Figure $4 \mathrm{~b}$ ). BINA administration had no effect on the number of active lever presses (Figure 4b).

Experiment 3: effects of BINA administration on brain reward function and cocaine-induced reward enhancement. Before the initiation of administration of BINA or 
BINA combined with cocaine administration, the absolute values of baseline reward thresholds were $147.78 \pm 11.08 \mu \mathrm{A}$ and $158.89 \pm 10.34 \mu \mathrm{A}$, respectively, and response latencies were $3.43 \pm 0.13 \mathrm{~s}$ and $3.47 \pm 0.14 \mathrm{~s}$, respectively. One-way ANOVAs on baseline threshold and latency values derived during the baseline days of testing between the drug treatment days indicated no statistically significant effects, showing the stability of baseline thresholds and latencies during the experiment (data not shown).

An overall two-way ANOVA on thresholds revealed a significant main effect of BINA $\left(\mathrm{F}_{3,30}=23.68, p<0.001\right)$, a main effect of Cocaine $\left(\mathrm{F}_{1,10}=43.15, p<0.01\right)$, but no $B I N A \times$ Cocaine interaction. When administered alone, BINA significantly elevated reward thresholds at doses of 20 and $40 \mathrm{mg} / \mathrm{kg}$ (Figure 5a). Cocaine administration significantly lowered ICSS thresholds when co-administered with vehicle or $10 \mathrm{mg} / \mathrm{kg}$ BINA (Figure $5 \mathrm{a}$ ). BINA administration at the highest doses $(20$ and $40 \mathrm{mg} / \mathrm{kg}$ ) attenuated cocaine-induced threshold lowering ( $p<0.05$, Figure 5a).
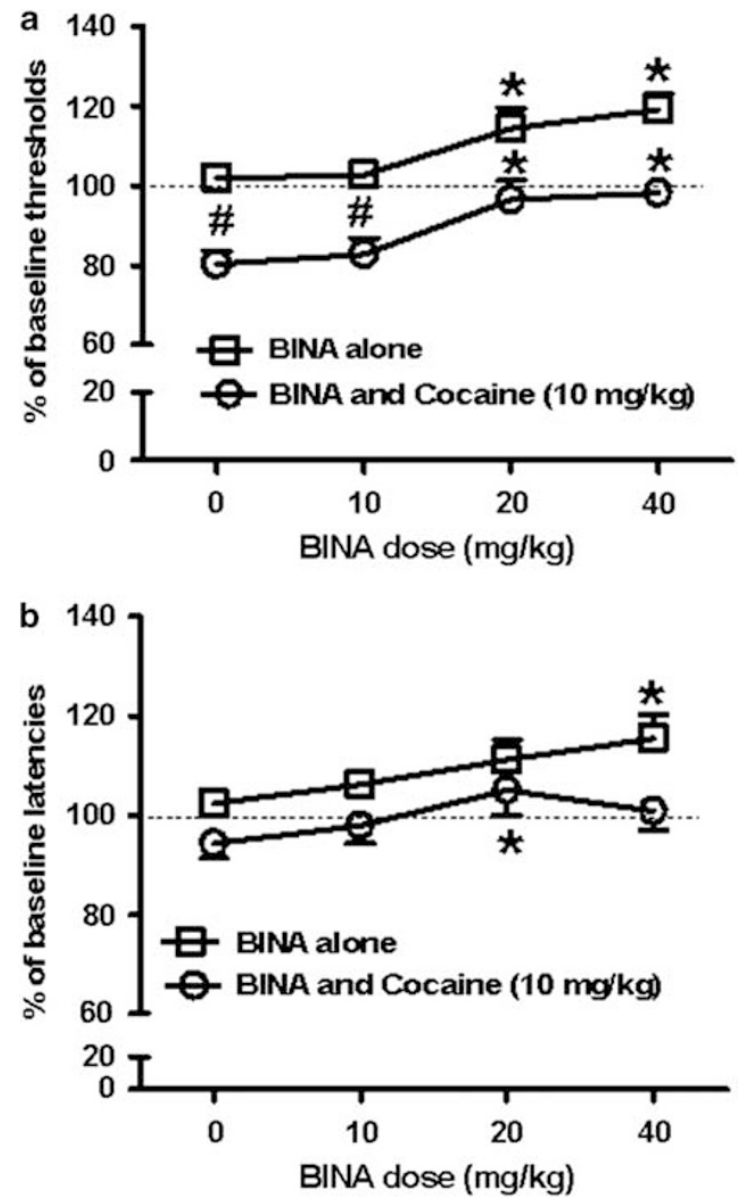

Figure 5 Effects of BINA on (a) brain reward thresholds and (b) response latencies under baseline conditions and after co-administration with cocaine. Data are expressed as a percentage of baseline ICSS thresholds and response latencies (mean $\pm \mathrm{SEM}$ ) before each drug administration (see text for baseline values). $*_{p}<0.05$, significant differences from the vehicle condition when BINA was administered either alone (ie, baseline conditions) or combined with cocaine; ${ }^{\#} p<0.05$, significant differences between values after BINA administration alone and values after administration of BINA combined with cocaine.
An overall two-way ANOVA on response latencies showed a significant main effect of $\operatorname{BINA}\left(\mathrm{F}_{3,30}=3.63\right.$, $p<0.05)$ and a main effect of Cocaine $\left(\mathrm{F}_{1,10}=10.96\right.$, $p<0.01$ ), but no BINA $\times$ Cocaine interaction. Post hoc tests indicated that response latencies were significantly increased after administration of $40 \mathrm{mg} / \mathrm{kg}$ BINA compared with the vehicle condition (Figure 5b). Administration of $20 \mathrm{mg} / \mathrm{kg}$ BINA reversed the cocaine-induced decrease in response latencies $(p<0.05$, Figure $5 b)$.

\section{DISCUSSION}

This study showed that systemic administration of the mGluR2 PAM BINA decreased cocaine self-administration in both ShA and LgA rats. A similar effect was observed after administration of the mGluR2/3 agonist LY379268, which also decreased cocaine self-administration in both ShA and LgA rats. Importantly, BINA administration had no effect on food-maintained responding at any of the doses tested, whereas LY379268 decreased food responding at the highest dose used $(6 \mathrm{mg} / \mathrm{kg})$. Furthermore, BINA administration attenuated cue-induced reinstatement of cocaine, but not food, self-administration in a subset of LgA rats that showed cue-induced reinstatement of reinforcer-seeking. Finally, acute administration of BINA elevated ICSS thresholds when administered alone and attenuated the rewardenhancing effects of noncontingent cocaine in an additive manner.

The mGluR2 PAM BINA significantly decreased cocaine self-administration in both ShA and LgA rats when administered at doses of 20 and $40 \mathrm{mg} / \mathrm{kg}$. This is one of the first demonstrations that an mGluR2 PAM decreased the reinforcing effects of acute cocaine, with the effects in ShA rats tending to be more pronounced than in $\operatorname{LgA}$ rats when data are expressed as either percentage of baseline (Figure 3) or absolute values (data not shown). This finding shows the resistance of LgA rats' responding for cocaine to manipulations that decrease the rewarding properties of cocaine in ShA rats. Similar to BINA, administration of the mGluR2/3 agonist LY379268 at the highest dose of $6 \mathrm{mg} / \mathrm{kg}$ decreased cocaine self-administration in both ShA and $\operatorname{LgA}$ rats, whereas the lower dose of $3 \mathrm{mg} / \mathrm{kg}$ was effective only in ShA rats. These results again indicate a trend for smaller effects of manipulations that decrease the reinforcing effects of cocaine in LgA rats. Our findings are consistent with literature showing that LY379268 decreased cocaine selfadministration in ShA rats at the $3 \mathrm{mg} / \mathrm{kg}$ dose (Baptista et al, 2004) and dose-dependently $(0.3,0.56$, and $1 \mathrm{mg} / \mathrm{kg})$ decreased cocaine self-administration in squirrel monkeys with an 8 -month history of daily 2 -h cocaine self-administration sessions (Adewale et al, 2006). In summary, the effects of BINA on cocaine self-administration were more robust in ShA rats than in LgA rats, and higher doses of LY379268 were needed to decrease cocaine intake in $\operatorname{LgA}$ compared with ShA rats. This pattern of results may be attributed to a shift of stability state in reward or aversion processes with the development of drug dependence (Koob et al, 2004). Consistent with this possibility, $\operatorname{LgA}$ rats showed tolerance to the psychomotor effects of a cocaine challenge after a period of abstinence compared with ShA rats (Ben-Shahar et al, 2005). Furthermore, LgA 
rats showed more pronounced cocaine withdrawal signs compared with ShA rats, reflected in elevations in brain reward thresholds, after prolonged exposure to cocaine selfadministration (Ahmed et al, 2002), and a two- to threefold increase in stress reactivity measured by the defensive burying behavior (Aujla et al, 2008).

In addition to cocaine self-administration, systemic or central administration of LY379268 also decreased nicotine (Liechti et al, 2007) and alcohol (Backstrom and Hyytia, 2005) self-administration, whereas it had no effect on heroin self-administration (Bossert et al, 2005). These findings indicate that activation of mGluR2/3 may be effective specifically against the reinforcing properties of psychostimulants, but not opiates. The effects of BINA on the reinforcing effects of other drugs of abuse are not known and merit further investigation.

In contrast to cocaine self-administration, BINA administration had no effect on food-maintained responding. The effects of pharmacological manipulations on lever responding are dependent on baseline response rates, and drugs are generally more likely to decrease higher response rates than lower rates (Sanger and Blackman, 1976). The dorsal striatum and nucleus accumbens are critically involved in motor control (Mogenson et al, 1980), and anatomical studies report that these brain structures express high levels of mGluR2 and mGluR3 (Ohishi et al, 1998; Tamaru et al, 2001). However, low or high response rates during baseline performance are unlikely to account for the present results. BINA specifically decreased cocaine self-administration in ShA (22 responses per $1 \mathrm{~h}$ ) and LgA (25 responses per $1 \mathrm{~h}$ or 129 responses per $6 \mathrm{~h}$ ) rats but had no effect on food responding (100 responses per $1 \mathrm{~h}$ ). These results indicate that BINA did not alter the rewarding value of food in foodrestricted rats or their motor ability to perform the task. Alternatively, food-maintained responding may be less sensitive to the effects of BINA because in food-restricted rats the motivation to respond for food and/or a food-paired cue may be greater than the motivation to respond for cocaine and/or a cocaine-paired cue. However, in contrast to the effects of BINA and consistent with our previous data (Liechti et al, 2007), LY379268 decreased responding for food pellets in food-restricted rats, indicating that the differential effects of BINA and LY379268 were independent of hunger state in food-restricted rats. This decrease in food responding by LY379268 suggests that administration of the mGluR2/3 agonist, but not the mGluR2 PAM, decreased motivation for a natural reinforcer. Nevertheless, other literature reports that LY379268 (1 or $3 \mathrm{mg} / \mathrm{kg}$ ) had no effect on sucrose intake in free-fed rats (Baptista et al, 2004) or condensed milk intake in food-restricted rats (Bossert et al, 2006b). These findings suggest that higher doses of LY379268 may be needed to decrease responding for food in less motivated free-feeding rats or for palatable reinforcers.

To evaluate possible differential effects of BINA on cocaine-seeking behavior in $\operatorname{LgA}$ and ShA rats, in this study rats were contingently presented with a cue light associated with cocaine infusion during 1-h reinstatement test sessions. Interestingly, subgroups of ShA and $\operatorname{LgA}$ rats that reinstated or did not reinstate cocaine-seeking behavior after vehicle administration were identified based on a median split, as well as a predefined criterion. According to the predefined criterion (see Materials and methods, and
Results for details), $61 \%$ (8 out of 13) of LgA rats showed cue-induced cocaine-seeking behavior after vehicle administration, whereas only $25 \%$ ( 3 out of 12 ) of ShA rats showed significant reinstatement of cocaine self-administration. In other studies, a more effective compound cue light + tone (Kippin et al, 2006; Lu et al, 2007) or discrete discriminatory cues $\left(\mathrm{CS}^{+} v s \mathrm{CS}^{-}\right)$associated with cocaine availability vs saline (Baptista et al, 2004) were used to reinstate cocaine self-administration in LgA or ShA rats during 2-h reinstatement sessions. Somewhat consistent with our results, previous studies have shown that, compared with ShA rats, LgA rats showed more robust reinstatement of cocaine self-administration when being subjected to cocaine-associated compound cues (Kippin et al, 2006) and noncontingent cocaine injections (Mantsch et al, 2004; Ferrario et al, 2005; Ahmed and Cador, 2006; Knackstedt and Kalivas, 2007), or when re-exposed to extended 6-h cocaine self-administration sessions after abstinence (Ahmed and Koob, 1998). In addition, LgA rats that selfadministered heroin showed greater levels of stress-induced reinstatement of heroin-seeking behavior than ShA rats (Ahmed et al, 2000). Altogether these findings suggest that LgA rats showed higher motivation for cocaine selfadministration after exposure to cocaine-associated cues compared with ShA rats. This interpretation is consistent with our previous work showing that $\operatorname{LgA}$ rats showed increased motivation to self-administer cocaine compared with ShA rats, reflected by increased breakpoints for cocaine under a progressive-ratio schedule of reinforcement (Paterson and Markou, 2003). Furthermore, presentation of an aversive CS suppressed cocaine seeking in ShA, but not $\operatorname{LgA}$, rats (Vanderschuren and Everitt, 2004).

Interestingly, the mGluR2 PAM BINA, at all doses used, significantly attenuated cue-induced reinstatement of cocaine-seeking behavior in subsets of both $\mathrm{ShA}$ and $\operatorname{LgA}$ rats that showed cue-induced reinstatement according to the median split subgrouping. Furthermore, when the other criterion of reinstatement that involved comparison with the number of lever presses during the last days of extinction was used for subgrouping of the subjects, BINA significantly attenuated cue-induced reinstatement of cocaine-seeking behavior in LgA rats at the doses of 20 and $40 \mathrm{mg} / \mathrm{kg}$. Thus, the present data showed clear decrease in cue-induced cocaine seeking after BINA administration. Similar to the effects of systemic BINA administration, systemic and central nucleus of the amygdala injections of LY379268 attenuated cue-induced cocaine-seeking behavior in LgA rats after 21, but not 3, days of abstinence from cocaine (Lu et al, 2007). In addition, LY379268 attenuated cue(Baptista et al, 2004; Lu et al, 2007) and cocaine- (Adewale et al, 2006; Peters and Kalivas, 2006) induced reinstatement of cocaine self-administration in ShA rats. Moreover, LY379268 administration attenuated heroin- (Bossert et al, 2004, 2005, 2006a), nicotine- (Liechti et al, 2007), and alcohol- (Backstrom and Hyytia, 2005; Zhao et al, 2006) seeking behavior in rats with limited access to drug self-administration.

Importantly, our results have shown that BINA specifically decreased cue-induced cocaine-seeking behavior, without affecting cue-induced food-seeking behavior. By contrast, LY379268 reduced cue-induced food pellet(Peters and Kalivas, 2006), condensed milk- (Baptista et al, 
2004), and sucrose- (Bossert et al, 2006b) seeking behavior, without impairing locomotion (Cartmell et al, 1999, 2000; Bossert et al, 2006b). These findings indicate that independent of hunger level, administration of an mGluR2/3 agonist decreased motivation for a natural reinforcer in both freefed (Baptista et al, 2004) and food-restricted (Peters and Kalivas, 2006; Bossert et al, 2006b) rats, whereas the mGluR2 positive modulator BINA specifically decreased cue-induced cocaine-, but not food-, seeking behavior, suggesting an improved behavioral profile of BINA compared with mGluR2/3 agonists.

Although BINA had no effect on food-maintained responding, it significantly decreased the rewarding effects of electrical brain stimulation, another non-drug reinforcer, reflected by significantly elevated ICSS thresholds. In addition, response latencies were significantly increased after BINA $(40 \mathrm{mg} / \mathrm{kg})$ administration compared with vehicle. Similar effects have been reported for the mGluR2/3 agonists LY379268 (Liechti and Markou, 2007) and LY314582 (Harrison et al, 2002), indicating mild aversive or anhedonic effects. Furthermore, BINA attenuated the threshold-lowering effect of noncontingent cocaine, although this effect of BINA was additive rather than interactive because the same BINA doses when administered alone mildly impaired brain reward function. It should be noted that the brain stimulation study was conducted in animals that were cocaine naïve and did not have self-administration experience. As cocaine administration has been shown to alter mGluR2 function (for reviews, see Gass and Olive, 2008; Knackstedt and Kalivas, 2009), there is a possibility that the effects of BINA on cocaine-induced enhancement of brain reward function may be altered in rats with extensive exposure to cocaine. Nevertheless, the present data set suggests that perhaps BINA decreased the reinforcing effects of cocaine partly because of its mild anhedonic effect and/or because of blockade of cocaine-induced reward enhancement.

Repeated cocaine exposure results in long-lasting molecular and cellular adaptations in the corticostriatal circuit that contributes to behavioral changes associated with cocaine addiction (for review, see Hyman et al, 2006; Feltenstein and See, 2008). A decrease in basal glutamate levels was found after cocaine self-administration accompanied by an increased release of glutamate during reinstatement (for reviews, see Gass and Olive, 2008; Knackstedt and Kalivas, 2009). Multiple pools of extracellular glutamate have been identified. In addition to synaptic glutamate, maintained by vesicular release, extrasynaptic glutamate is sustained by nonvesicular release that regulates neurotransmission by mGluR2/3 stimulation (Madayag et al, 2007; Knackstedt and Kalivas, 2009). Thus, the reduction in extracellular glutamate levels in the nucleus accumbens may be attributable to desensitization of presynaptic mGluR2/3, and thus decreased inhibition of glutamate release by these receptors (Swanson et al, 2001; Xi et al, 2002b; Xie and Steketee, 2008, 2009). Electrophysiological findings have shown that in the prefrontal cortex, mGluR2/3 agonists suppressed the induction of excitatory postsynaptic potentials/currents (Marek et al, 2000), and this effect was potentiated by BINA (Benneyworth et al, 2007), further indicating a presynaptic mechanism for mGluR2 in suppressing glutamate release. In addition, in the nucleus accumbens, basal extracellular glutamate levels are regulated by the glutamate cysteine-glutamate antiporter (xc system), which exchanges extracellular cysteine for intracellular glutamate (Baker et al, 2002; Knackstedt and Kalivas, 2009). The xc system may be critical in the capacity of extrasynaptic glutamate to regulate corticostriatal signaling in both normal and pathological addictive states (Madayag et al, 2007; Knackstedt and Kalivas, 2009). That is, nonvesicular release from cysteine-glutamate exchange maintains basal extracellular glutamate in the nucleus accumbens (Baker et al, 2002; Xi et al, 2002b), thereby regulating the extent of mGluR2/3 stimulation (Baker et al, 2002; Melendez et al, 2005; Moran et al, 2005). Administration of mGluR2/3 agonists reduced extracellular glutamate levels, whereas mGluR2/3 antagonists increased extracellular glutamate (Xi et al, 2002a; Xie and Steketee, 2008), suggesting that mGluR $2 / 3$ in the prefrontal cortex tonically inhibited mesocorticolimbic glutamate transmission. Repeated cocaine administration downregulated the xc system, resulting in reduced basal and increased cocaineevoked glutamate in the nucleus accumbens of cocainewithdrawn animals (Baker et al, 2003). Furthermore, blockade of cysteine-glutamate exchange mimicked the effects of withdrawal from repeated cocaine on extracellular glutamate (Baker et al, 2003). By contrast, administration of $\mathrm{N}$-acetylcysteine, a cysteine pro-drug, restored basal glutamate levels and prevented both cocaine-primed reinstatement and the increase in extracellular glutamate observed during reinstatement of cocaine-seeking behavior (Baker et al, 2003; Madayag et al, 2007). Similarly, our previous findings with nicotine showed that nicotine self-administration downregulated mGluR $2 / 3$ function in corticolimbic brain sites $24 \mathrm{~h}$ after the cessation of nicotine selfadministration (Liechti et al, 2007), and the cysteineglutamate exchanger and the glial glutamate transporter were downregulated after nicotine self-administration (Knackstedt et al, 2009). Accordingly, $N$-acetylcysteine reduced the number of cigarettes smoked in a small double-blind clinical trial when alcohol consumption was taken into account (Knackstedt et al, 2010). Finally, LY379268 blocked the increased overflow of glutamate and dopamine in the nucleus accumbens induced by repeated exposure to another psychostimulant, amphetamine (Kim et al, 2005). Altogether, these data indicate that psychostimulant-induced neuroadaptations in glutamate system function include a combination of reduced baseline glutamate levels coupled with decreased mGluR2/3 function, with the latter contributing to loss of regulatory feedback control on synaptic glutamate release during activation induced by additional drug administration or exposure to environmental stimuli that lead to reinstatement of drug seeking (Kalivas, 2004; Markou, 2007; Gass and Olive, 2008; Knackstedt and Kalivas, 2009).

In summary, the present findings suggest a specific role for mGluR2 in cocaine-related behaviors, such as cocaine self-administration and cue-induced reinstatement of cocaine seeking, without affecting behaviors motivated by a natural food reinforcer. Furthermore, mGluR2 PAMs may block/counteract the reward-enhancing effects of drugs of abuse, and thus remove an additional source of motivation to use drugs, such as cocaine. The specificity of the effects of BINA on cocaine responding and cocaine seeking, but not 
food responding or food seeking, suggests that mGluR2 PAMs are a promising new approach for the treatment of different aspects of cocaine dependence and warrant further exploration in both the preclinical and clinical domains.

\section{ACKNOWLEDGEMENTS}

This work was supported by National Institutes of Health grant R01 DA023926 to NC. We thank Ms Kim Edwards and Mrs Jessica Benedict for technical assistance and $\mathrm{Mr}$ Michael Arends for editorial assistance.

\section{DISCLOSURE}

AM has received contract research support from Intracellular Therapeutics, Lundbeck Research USA, Bristol-Myers Squibb, F Hoffman-La Roche, Pfizer, and Astra-Zeneca and honorarium/consulting fees from Abbott $\mathrm{GmbH}$ and Company, AstraZeneca, and Pfizer during the past 3 years. AM and SS have a patent application on metabotropic glutamate receptors and drug dependence. PJC receives research support, including salary support, from Seaside Therapeutics and Johnson and Johnson and has received consulting fees or speaking honoraria from Eli Lilly and Company, Invitrogen, Roche Pharmaceutical, Cephalon, AstraZeneca, Bristol-Myers Squibb, Addex, Forest Research Institute, LEK Consulting, Merck and Company, Epix Pharmaceuticals, AMRI, Evotec, Millipore, Genentech, IMS Health, Sepracor, Seaside Therapeutics, Lundbeck Research, Otsuka Pharmaceuticals, Prestwich Pharmaceuticals, Primary Insight, The Frankel Group, Metastatix, GlaxoSmithKline, Adolor, Abbott Laboratories, Merck Serono, Johnson and Johnson, Solvay, and PureTech during the past 3 years. PJC is an inventor on multiple patents and pending patent applications on specific allosteric modulators of GPCRs, none of which is included in this study. NC has received research support from Brain Cells and honorarium/consulting fees from Vertex Pharmaceuticals during the past 3 years. The remaining authors declare no conflict of interest.

\section{REFERENCES}

Adewale AS, Platt DM, Spealman RD (2006). Pharmacological stimulation of group II metabotropic glutamate receptors reduces cocaine self-administration and cocaine-induced reinstatement of drug seeking in squirrel monkeys. J Pharmacol Exp Ther 318: 922-931.

Ahmed SH, Cador M (2006). Dissociation of psychomotor sensitization from compulsive cocaine consumption. Neuropsychopharmacology 31: 563-571.

Ahmed SH, Kenny PJ, Koob GF, Markou A (2002). Neurobiological evidence for hedonic allostasis associated with escalating cocaine use. Nat Neurosci 5: 625-626.

Ahmed SH, Koob GF (1998). Transition from moderate to excessive drug intake: change in hedonic set point. Science 282: 298-300.

Ahmed SH, Walker JR, Koob GF (2000). Persistent increase in the motivation to take heroin in rats with a history of drug escalation. Neuropsychopharmacology 22: 413-421.

American Psychiatric Association (1994). Diagnostic and Statistical Manual of Mental Disorders, 4th edn. American Psychiatric Press: Washington, DC.
Anwyl R (1999). Metabotropic glutamate receptors: electrophysiological properties and role in plasticity. Brain Res Brain Res Rev 29: 83-120.

Aujla H, Martin-Fardon R, Weiss F (2008). Rats with extended access to cocaine exhibit increased stress reactivity and sensitivity to the anxiolytic-like effects of the mGluR $2 / 3$ agonist LY379268 during abstinence. Neuropsychopharmacology 33: 1818-1826.

Backstrom P, Hyytia P (2005). Suppression of alcohol selfadministration and cue-induced reinstatement of alcohol seeking by the mGlu2/3 receptor agonist LY379268 and the mGlu8 receptor agonist (S)-3,4-DCPG. Eur J Pharmacol 528: 110-118.

Baker DA, McFarland K, Lake RW, Shen H, Tang XC, Toda S et al (2003). Neuroadaptations in cystine-glutamate exchange underlie cocaine relapse. Nat Neurosci 6: 743-749.

Baker DA, Shen H, Kalivas PW (2002). Cystine/glutamate exchange serves as the source for extracellular glutamate: modifications by repeated cocaine administration. Amino Acids 23: 161-162.

Baptista MA, Martin-Fardon R, Weiss F (2004). Preferential effects of the metabotropic glutamate $2 / 3$ receptor agonist LY379268 on conditioned reinstatement versus primary reinforcement: comparison between cocaine and a potent conventional reinforcer. J Neurosci 24: 4723-4727.

Ben-Shahar O, Moscarello JM, Jacob B, Roarty MP, Ettenberg A (2005). Prolonged daily exposure to i.v. cocaine results in tolerance to its stimulant effects. Pharmacol Biochem Behav 82: 411-416.

Benneyworth MA, Xiang Z, Smith RL, Garcia EE, Conn PJ, Sanders-Bush E (2007). A selective positive allosteric modulator of metabotropic glutamate receptor subtype 2 blocks a hallucinogenic drug model of psychosis. Mol Pharmacol 72: 477-484.

Bespalov AY, Dravolina OA, Sukhanov I, Zakharova E, Blokhina E, Zvartau E et al (2005). Metabotropic glutamate receptor (mGluR5) antagonist MPEP attenuated cue- and scheduleinduced reinstatement of nicotine self-administration behavior in rats. Neuropharmacology 49(Suppl 1): 167-178.

Bonnefous C, Vernier JM, Hutchinson JH, Gardner MF, Cramer M, James JK et al (2005). Biphenyl-indanones: allosteric potentiators of the metabotropic glutamate subtype 2 receptor. Bioorg Med Chem Lett 15: 4354-4358.

Bossert JM, Busch RF, Gray SM (2005). The novel mGluR2/3 agonist LY379268 attenuates cue-induced reinstatement of heroin seeking. Neuroreport 16: 1013-1016.

Bossert JM, Gray SM, Lu L, Shaham Y (2006a). Activation of group II metabotropic glutamate receptors in the nucleus accumbens shell attenuates context-induced relapse to heroin seeking. Neuropsychopharmacology 31: 2197-2209.

Bossert JM, Liu SY, Lu L, Shaham Y (2004). A role of ventral tegmental area glutamate in contextual cue-induced relapse to heroin seeking. J Neurosci 24: 10726-10730.

Bossert JM, Poles GC, Sheffler-Collins SI, Ghitza UE (2006b). The mGluR2/3 agonist LY379268 attenuates context- and discrete cue-induced reinstatement of sucrose seeking but not sucrose self-administration in rats. Behav Brain Res 173: 148-152.

Cartmell J, Monn JA, Schoepp DD (1999). The metabotropic glutamate $2 / 3$ receptor agonists LY354740 and LY379268 selectively attenuate phencyclidine versus d-amphetamine motor behaviors in rats. J Pharmacol Exp Ther 291: 161-170.

Cartmell J, Monn JA, Schoepp DD (2000). Attenuation of specific PCP-evoked behaviors by the potent $\mathrm{mGlu} 2 / 3$ receptor agonist, LY379268 and comparison with the atypical antipsychotic, clozapine. Psychopharmacology (Berl) 148: 423-429.

Cartmell J, Schoepp DD (2000). Regulation of neurotransmitter release by metabotropic glutamate receptors. J Neurochem 75: 889-907.

Chaudhri N, Caggiula AR, Donny EC, Booth S, Gharib M, Craven L et al (2006). Operant responding for conditioned and unconditioned 
reinforcers in rats is differentially enhanced by the primary reinforcing and reinforcement-enhancing effects of nicotine. Psychopharmacology (Berl) 189: 27-36.

Conn PJ, Pin JP (1997). Pharmacology and functions of metabotropic glutamate receptors. Annu Rev Pharmacol Toxicol 37: 205-237.

Dackis CA, O’Brien CP (2001). Cocaine dependence: a disease of the brain's reward centers. J Subst Abuse Treat 21: 111-117.

Epstein DH, Preston KL, Stewart J, Shaham Y (2006). Toward a model of drug relapse: an assessment of the validity of the reinstatement procedure. Psychopharmacology (Berl) 189: $1-16$.

Esposito RU, Motola AH, Kornetsky C (1978). Cocaine: acute effects on reinforcement thresholds for self-stimulation behavior to the medial forebrain bundle. Pharmacol Biochem Behav 8: 437-439.

Feltenstein MW, See RE (2008). The neurocircuitry of addiction: an overview. Br J Pharmacol 154: 261-274.

Ferrario CR, Gorny G, Crombag HS, Li Y, Kolb B, Robinson TE (2005). Neural and behavioral plasticity associated with the transition from controlled to escalated cocaine use. Biol Psychiatry 58: 751-759.

Frank RA, Martz S, Pommering T (1988). The effect of chronic cocaine on self-stimulation train-duration thresholds. Pharmacol Biochem Behav 29: 755-758.

Galici R, Echemendia NG, Rodriguez AL, Conn PJ (2005). A selective allosteric potentiator of metabotropic glutamate (mGlu) 2 receptors has effects similar to an orthosteric mGlu2/3 receptor agonist in mouse models predictive of antipsychotic activity. J Pharmacol Exp Ther 315: 1181-1187.

Galici R, Jones CK, Hemstapat K, Nong Y, Echemendia NG, Williams LC et al (2006). Biphenyl-indanone A, a positive allosteric modulator of the metabotropic glutamate receptor subtype 2, has antipsychotic- and anxiolytic-like effects in mice. J Pharmacol Exp Ther 318: 173-185.

Gass JT, Olive MF (2008). Glutamatergic substrates of drug addiction and alcoholism. Biochem Pharmacol 75: 218-265.

Govek SP, Bonnefous C, Hutchinson JH, Kamenecka T, McQuiston J, Pracitto R et al (2005). Benzazoles as allosteric potentiators of metabotropic glutamate receptor 2 (mGluR2): efficacy in an animal model for schizophrenia. Bioorg Med Chem Lett 15: 4068-4072.

Harrison AA, Gasparini F, Markou A (2002). Nicotine potentiation of brain stimulation reward reversed by $\mathrm{DH} \beta \mathrm{E}$ and $\mathrm{SCH} 23390$, but not by eticlopride, LY 314582 or MPEP in rats. Psychopharmacology (Berl) 160: 56-66.

Hemstapat K, Da Costa H, Nong Y, Brady AE, Luo Q, Niswender CM et al (2007). A novel family of potent negative allosteric modulators of group II metabotropic glutamate receptors. J Pharmacol Exp Ther 322: 254-264.

Hu E, Chua PC, Tehrani L, Nagasawa JY, Pinkerton AB, Rowe BA et al (2004). Pyrimidine methyl anilines: selective potentiators for the metabotropic glutamate 2 receptor. Bioorg Med Chem Lett 14: 5071-5074.

Hyman SM, Garcia M, Sinha R (2006). Gender specific associations between types of childhood maltreatment and the onset, escalation and severity of substance use in cocaine dependent adults. Am J Drug Alcohol Abuse 32: 655-664.

Johnson BG, Wright RA, Arnold MB, Wheeler WJ, Ornstein PL, Schoepp DD (1999). [ $\left.{ }^{3} \mathrm{H}\right]-\mathrm{LY} 341495$ as a novel antagonist radioligand for group II metabotropic glutamate (mGlu) receptors: characterization of binding to membranes of mGlu receptor subtype expressing cells. Neuropharmacology 38: 1519-1529.

Johnson MP, Baez M, Jagdmann Jr GE, Britton TC, Large TH, Callagaro DO et al (2003). Discovery of allosteric potentiators for the metabotropic glutamate 2 receptor: synthesis and subtype selectivity of $N$-(4-(2-methoxyphenoxy)phenyl)- $N$-(2,2,2trifluoroethylsulfonyl)pyrid-3-ylmethylamine. $J$ Med Chem 46: 3189-3192.

Johnson MP, Barda D, Britton TC, Emkey R, Hornback WJ, Jagdmann GE et al (2005). Metabotropic glutamate 2 receptor potentiators: receptor modulation, frequency-dependent synaptic activity, and efficacy in preclinical anxiety and psychosis model(s). Psychopharmacology (Berl) 179: 271-283.

Kalivas PW (2004). Glutamate systems in cocaine addiction. Curr Opin Pharmacol 4: 23-29.

Kalivas PW (2009). The glutamate homeostasis hypothesis of addiction. Nat Rev Neurosci 10: 561-572.

Kalivas PW, Duffy P (1998). Repeated cocaine administration alters extracellular glutamate in the ventral tegmental area. J Neurochem 70: 1497-1502.

Kalivas PW, Volkow ND (2005). The neural basis of addiction: a pathology of motivation and choice. Am J Psychiatry 162: 1403-1413.

Katz JL, Higgins ST (2003). The validity of the reinstatement model of craving and relapse to drug use. Psychopharmacology (Berl) 168: 21-30 [erratum: 168: 244].

Kenny PJ (2007). Brain reward systems and compulsive drug use. Trends Pharmacol Sci 28: 135-141.

Kenny PJ, Chen SA, Kitamura O, Markou A, Koob GF (2006). Conditioned withdrawal drives heroin consumption and decreases reward sensitivity. J Neurosci 26: 5894-5900.

Kenny PJ, Markou A (2004). The ups and downs of addiction: role of metabotropic glutamate receptors. Trends Pharmacol Sci 25: 265-272.

Kenny PJ, Markou A (2006). Nicotine self-administration acutely activates brain reward systems and induces a long-lasting increase in reward sensitivity. Neuropsychopharmacology 31: 1203-1211.

Kenny PJ, Polis I, Koob GF, Markou A (2003). Low dose cocaine self-administration transiently increases but high dose cocaine persistently decreases brain reward function in rats. Eur J Neurosci 17: 191-195.

Kim JH, Austin JD, Tanabe L, Creekmore E, Vezina P (2005). Activation of group II mGlu receptors blocks the enhanced drug taking induced by previous exposure to amphetamine. Eur $J$ Neurosci 21: 295-300 [erratum: 25: 908].

Kippin TE, Fuchs RA, See RE (2006). Contributions of prolonged contingent and noncontingent cocaine exposure to enhanced reinstatement of cocaine seeking in rats. Psychopharmacology (Berl) 187: 60-67.

Knackstedt LA, Kalivas PW (2007). Extended access to cocaine self-administration enhances drug-primed reinstatement but not behavioral sensitization. J Pharmacol Exp Ther 322: 1103-1109.

Knackstedt LA, Kalivas PW (2009). Glutamate and reinstatement. Curr Opin Pharmacol 9: 59-64.

Knackstedt LA, LaRowe S, Mardikian P, Malcolm R, Upadhyaya H, Hedden $S$ et al (2009). The role of cystine-glutamate exchange in nicotine dependence in rats and humans. Biol Psychiatry 65: 841-845.

Knackstedt LA, Melendez RI, Kalivas PW (2010). Ceftriaxone restores glutamate homeostasis and prevents relapse to cocaine seeking. Biol Psychiatry 67: 81-84.

Kokkinidis L, McCarter BD (1990). Postcocaine depression and sensitization of brain-stimulation reward: analysis of reinforcement and performance effects. Pharmacol Biochem Behav 36: 463-471.

Koob GF (2009). Neurobiological substrates for the dark side of compulsivity in addiction. Neuropharmacology 56(Suppl 1): 18-31.

Koob GF, Ahmed SH, Boutrel B, Chen SA, Kenny PJ, Markou A et al (2004). Neurobiological mechanisms in the transition from drug use to drug dependence. Neurosci Biobehav Rev 27: 739-749. 
Kornetsky C, Esposito RU, McLean S, Jacobson JO (1979). Intracranial self-stimulation thresholds: a model for the hedonic effects of drugs of abuse. Arch Gen Psychiatry 36: 289-292.

Lee B, Platt DM, Rowlett JK, Adewale AS, Spealman RD (2005). Attenuation of behavioral effects of cocaine by the metabotropic glutamate receptor 5 antagonist 2-methyl-6-(phenylethynyl)pyridine in squirrel monkeys: comparison with dizocilpine. J Pharmacol Exp Ther 312: 1232-1240.

Leshner AI (1997). Addiction is a brain disease, and it matters. Science 278: 45-47.

Liechti ME, Lhuillier L, Kaupmann K, Markou A (2007). Metabotropic glutamate $2 / 3$ receptors in the ventral tegmental area and the nucleus accumbens shell are involved in behaviors relating to nicotine dependence. J Neurosci 27: 9077-9085.

Liechti ME, Markou A (2007). Metabotropic glutamate 2/3 receptor activation induced reward deficits but did not aggravate brain reward deficits associated with spontaneous nicotine withdrawal in rats. Biochem Pharmacol 74: 1299-1307.

Lu L, Uejima JL, Gray SM, Bossert JM, Shaham Y (2007). Systemic and central amygdala injections of the $\mathrm{mGluR}_{2 / 3}$ agonist LY379268 attenuate the expression of incubation of cocaine craving. Biol Psychiatry 61: 591-598.

Madayag A, Lobner D, Kau KS, Mantsch JR, Abdulhameed O, Hearing $\mathrm{M}$ et al (2007). Repeated $\mathrm{N}$-acetylcysteine administration alters plasticity-dependent effects of cocaine. J Neurosci 27: 13968-13976.

Mansvelder HD, McGehee DS (2000). Long-term potentiation of excitatory inputs to brain reward areas by nicotine. Neuron 27: 349-357.

Mantsch JR, Yuferov V, Mathieu-Kia AM, Ho A, Kreek MJ (2004). Effects of extended access to high versus low cocaine doses on self-administration, cocaine-induced reinstatement and brain mRNA levels in rats. Psychopharmacology (Berl) 175: 26-36.

Marek GJ, Wright RA, Schoepp DD, Monn JA, Aghajanian GK (2000). Physiological antagonism between 5-hydroxytryptami$\mathrm{ne}_{2 \mathrm{~A}}$ and group II metabotropic glutamate receptors in prefrontal cortex. J Pharmacol Exp Ther 292: 76-87.

Markou A (2007). Metabotropic glutamate receptor antagonists: novel therapeutics for nicotine dependence and depression? Biol Psychiatry 61: 17-22.

Markou A, Koob GF (1992). Construct validity of a self-stimulation threshold paradigm: effects of reward and performance manipulations. Physiol Behav 51: 111-119.

Markou A, Weiss F, Gold LH, Caine SB, Schulteis G, Koob GF (1993). Animal models of drug craving. Psychopharmacology (Berl) 112: 163-182.

Melendez RI, Vuthiganon J, Kalivas PW (2005). Regulation of extracellular glutamate in the prefrontal cortex: focus on the cystine glutamate exchanger and group I metabotropic glutamate receptors. J Pharmacol Exp Ther 314: 139-147.

Mello NK, Negus SS (1996). Preclinical evaluation of pharmacotherapies for treatment of cocaine and opioid abuse using drug self-administration procedures. Neuropsychopharmacology 14: 375-424.

Mogenson GJ, Jones DL, Yim CY (1980). From motivation to action: functional interface between the limbic system and the motor system. Prog Neurobiol 14: 69-97.

Monn JA, Valli MJ, Massey SM, Hansen MM, Kress TJ, Wepsiec JP et al (1999). Synthesis, pharmacological characterization, and molecular modeling of heterobicyclic amino acids related to (+)2-aminobicyclo[3.1.0] hexane-2,6-dicarboxylic acid (LY354740): identification of two new potent, selective, and systemically active agonists for group II metabotropic glutamate receptors. J Med Chem 42: 1027-1040.

Moran MM, McFarland K, Melendez RI, Kalivas PW, Seamans JK (2005). Cystine/glutamate exchange regulates metabotropic glutamate receptor presynaptic inhibition of excitatory transmission and vulnerability to cocaine seeking. J Neurosci 25: 6389-6393.

Niswender CM, Johnson KA, Luo Q, Ayala JE, Kim C, Conn PJ et al (2008). A novel assay of $\mathrm{G}_{\mathrm{i} / \mathrm{o}}$-linked $\mathrm{G}$ protein-coupled receptor coupling to potassium channels provides new insights into the pharmacology of the group III metabotropic glutamate receptors. Mol Pharmacol 73: 1213-1224.

O'Brien CP, Childress AR, Ehrman R, Robbins SJ (1998). Conditioning factors in drug abuse: can they explain compulsion? J Psychopharmacol 12: 15-22.

O'Brien CP, Gardner EL (2005). Critical assessment of how to study addiction and its treatment: human and non-human animal models. Pharmacol Ther 108: 18-58.

O'Brien CP, McLellan AT (1996). Myths about the treatment of addiction. Lancet 347: 237-240.

Ohishi H, Neki A, Mizuno N (1998). Distribution of a metabotropic glutamate receptor, mGluR2, in the central nervous system of the rat and mouse: an immunohistochemical study with a monoclonal antibody. Neurosci Res 30: 65-82.

Paterson NE, Markou A (2003). Increased motivation for selfadministered cocaine after escalated cocaine intake. Neuroreport 14: 2229-2232.

Paterson NE, Vlachou S, Guery S, Kaupmann K, Froestl W, Markou A (2008). Positive modulation of GABA(B) receptors decreased nicotine self-administration and counteracted nicotine-induced enhancement of brain reward function in rats. J Pharmacol Exp Ther 326: 306-314.

Pellegrino L, Pellegrino A, Cushman A (1986). A Stereotaxic Atlas of the Rat Brain, 2nd edn. Plenum Press: New York.

Peters J, Kalivas PW (2006). The group II metabotropic glutamate receptor agonist, LY379268, inhibits both cocaine- and food-seeking behavior in rats. Psychopharmacology (Berl) 186: 143-149.

Phillips AG, Fibiger HC (1990). Role of reward and enhancement of conditioned reward in persistence of responding for cocaine. Behav Pharmacol 1: 269-282.

Pinkerton AB, Cube RV, Hutchinson JH, Rowe BA, Schaffhauser H, Zhao X et al (2004). Allosteric potentiators of the metabotropic glutamate receptor 2 (mGlu2): part 1 . Identification and synthesis of phenyl-tetrazolyl acetophenones. Bioorg Med Chem Lett 14: 5329-5332.

Rice ME, Cragg SJ (2004). Nicotine amplifies reward-related dopamine signals in striatum. Nat Neurosci 7: 583-584.

Robbins TW, Watson BA, Gaskin M, Ennis C (1983). Contrasting interactions of pipradrol, d-amphetamine, cocaine, cocaine analogues, apomorphine and other drugs with conditioned reinforcement. Psychopharmacology (Berl) 80: 113-119.

Sanger DJ, Blackman DE (1976). Rate-dependent effects of drugs: a review of the literature. Pharmacol Biochem Behav 4: 73-83.

Schaffhauser H, Rowe BA, Morales S, Chavez-Noriega LE, Yin R, Jachec C et al (2003). Pharmacological characterization and identification of amino acids involved in the positive modulation of metabotropic glutamate receptor subtype 2. Mol Pharmacol 64: 798-810.

Schoepp DD (2001). Unveiling the functions of presynaptic metabotropic glutamate receptors in the central nervous system. J Pharmacol Exp Ther 299: 12-20.

Semenova S, Markou A (2003a). Cocaine-seeking behavior after extended cocaine-free periods in rats: role of conditioned stimuli. Psychopharmacology (Berl) 168: 192-200.

Semenova S, Markou A (2003b). Clozapine treatment attenuated somatic and affective signs of nicotine and amphetamine withdrawal in subsets of rats exhibiting hyposensitivity to the initial effects of clozapine. Biol Psychiatry 54: 1249-1264.

Shalev U, Grimm JW, Shaham Y (2002). Neurobiology of relapse to heroin and cocaine seeking: a review. Pharmacol Rev 54: 1-42.

Shiffman S, Ferguson SG, Gwaltney CJ, Balabanis MH, Shadel WG (2006). Reduction of abstinence-induced withdrawal and craving 
using high-dose nicotine replacement therapy. Psychopharmacology (Berl) 184: 637-644.

Swanson CJ, Baker DA, Carson D, Worley PF, Kalivas PW (2001). Repeated cocaine administration attenuates group I metabotropic glutamate receptor-mediated glutamate release and behavioral activation: a potential role for Homer. J Neurosci 21: 9043-9052.

Tamaru Y, Nomura S, Mizuno N, Shigemoto R (2001). Distribution of metabotropic glutamate receptor mGluR3 in the mouse CNS: differential location relative to pre- and postsynaptic sites. Neuroscience 106: 481-503.

Taylor JR, Robbins TW (1986). 6-Hydroxydopamine lesions of the nucleus accumbens, but not of the caudate nucleus, attenuate enhanced responding with reward-related stimuli produced by intra-accumbens d-amphetamine. Psychopharmacology (Berl) 90: 390-397.

Ungless MA, Whistler JL, Malenka RC, Bonci A (2001). Single cocaine exposure in vivo induces long-term potentiation in dopamine neurons. Nature 411: 583-587.

Vanderschuren LJ, Everitt BJ (2004). Drug seeking becomes compulsive after prolonged cocaine self-administration. Science 305: 1017-1019.

Weaver CD, Harden D, Dworetzky SI, Robertson B, Knox RJ (2004). A thallium-sensitive, fluorescence-based assay for detecting and characterizing potassium channel modulators in mammalian cells. J Biomol Screen 9: 671-677.
Weiss F (2005). Neurobiology of craving, conditioned reward and relapse. Curr Opin Pharmacol 5: 9-19.

Woolley ML, Pemberton DJ, Bate S, Corti C, Jones DN (2008). The mGlu2 but not the mGlu3 receptor mediates the actions of the mGluR2/3 agonist, LY379268, in mouse models predictive of antipsychotic activity. Psychopharmacology (Berl) 196: 431-440.

Xi ZX, Baker DA, Shen H, Carson DS, Kalivas PW (2002a). Group II metabotropic glutamate receptors modulate extracellular glutamate in the nucleus accumbens. J Pharmacol Exp Ther 300: 162-171.

Xi ZX, Ramamoorthy S, Baker DA, Shen H, Samuvel DJ, Kalivas PW (2002b). Modulation of group II metabotropic glutamate receptor signaling by chronic cocaine. J Pharmacol Exp Ther 303: 608-615.

Xie X, Steketee JD (2009). Effects of repeated exposure to cocaine on group II metabotropic glutamate receptor function in the rat medial prefrontal cortex: behavioral and neurochemical studies. Psychopharmacology (Berl) 203: 501-510.

Xie X, Steketee JD (2008). Repeated exposure to cocaine alters the modulation of mesocorticolimbic glutamate transmission by medial prefrontal cortex Group II metabotropic glutamate receptors. J Neurochem 107: 186-196.

Zhao Y, Dayas CV, Aujla H, Baptista MA, Martin-Fardon R, Weiss F (2006). Activation of group II metabotropic glutamate receptors attenuates both stress and cue-induced ethanolseeking and modulates c-fos expression in the hippocampus and amygdala. J Neurosci 26: 9967-9974.

Supplementary Information accompanies the paper on the Neuropsychopharmacology website (http://www.nature.com/npp) 